\title{
Los terremotos a la luz de la ciencia antigua: el testimonio de Apuleyo, Mund.18.329-332
}

\author{
Cristóbal MACÍAS \\ Universidad de Málaga \\ cmacias@uma.es
}

Recibido: 16 de septiembre de 2010

Aceptado: 15 de enero de 2011

\section{RESUMEN}

En el pseudo aristotélico Peri kosmou y en su versión latina el De mundo de Apuleyo aparece una clasificación de los terremotos sin parangón en la Antigüedad. Tras revisar en detalle los diversos estudios «científicos» de los terremotos que se hicieron entonces y las tipologías de seísmos que proponen, podemos afirmar que la clasificación del Peri kosmou es de origen estoico, lo cual nos podría ayudar a datar este pequeño tratado y a saber algo más sobre su posible influencia posterior.

Palabras clave: Terremotos. Meteorología. Peri kosmou. De mundo. Apuleyo.

MaCíAs, C. «Los terremotos a la luz de la ciencia antigua: el testimonio de Apuleyo, Mund.18.329332», Cuad. Fil. Clás. Estud. Lat. 31.1 (2011) 37-67.

\section{Earthquakes in the light of ancient science: the witness of Apuleius, Mund.18.329-332}

\begin{abstract}
In the pseudo-Aristotelian Peri kosmou and in its Latin version Apuleius' De mundo there is a classification of earthquakes unparalleled in Antiquity. After reviewing in detail the various «scientific» studies of earthquakes that were made in ancient world and the types that they suggest, we can say that the classification of Peri kosmou is Stoic in origin, which could help us to date this little treatise and also allows us to learn more about its possible influence later.
\end{abstract}

Keywords: Earthquakes. Meteorology. Peri kosmou. De mundo. Apuleius.

MACÍAS, C., «Earthquakes in the light of ancient science: the witness of Apuleius, Mund.18.329-332», Cuad. Fil. Clás. Estud. Lat. 31.1 (2011) 37-67.

Sumario 1. El De mundo en el contexto de la obra de Apuleyo. 2. Sobre la naturaleza y tipología de los terremotos según Apuleyo. 3. Las teorías antiguas sobre la naturaleza de los terremotos y su tipología hasta la época de Apuleyo. 3.1. Aristóteles. 3.2. Lucrecio. 3.3. Plinio el Viejo. 3.4. Séneca y su estudio sobre las posibles causas de los seísmos. 3.5. La tipología de los seismos de Séneca y el papel de Posidonio. 4. La tipología de los seísmos del Peri kosmou y el De mundo y su posible influencia. 5. Conclusión. 6. Referencias bibliográficas. 


\section{EL DE MUNDO EN EL CONTEXTO DE LA OBRA DE APULEYO}

A los lectores de la obra de Apuleyo, cuya familiaridad con el Madaurense se limite a su universalmente conocido Asinus aureus, a su Apologia o De magia y quizás al más citado de sus opuscula filosóficos, el dedicado al demon de Sócrates (De deo Socratis), les sorprenderá sin duda saber que a éste debemos una breve mención a los terremotos, incluida en el De mundo, traducción o más bien adaptación del pseudoaristotélico Peri kosmou, un tratado cosmológico ${ }^{1}$.

Aunque se ha discutido mucho acerca de la autoría apuleyana sobre el De mundo -sobre todo por las dudas sobre las razones que habrían llevado a nuestro autor a emprender la traducción de un tratado de índole peripatética, no platónica, y cuya temática parece no dominar del todo ${ }^{2}$, hoy día hay cierto consenso en considerarla auténtica, e incluso se ha apuntado que podría ser obra de juventud junto con el $D e$ Platone et eius dogmate, un resumen escolar de la filosofía platónica que debió aprender durante su estancia en Atenas ${ }^{3}$.

El De mundo, además, es interesante porque nos podría proporcionar uno de los pocos hitos seguros reconocibles en la nebulosa cronología de la vida y la obra apuleyana. En efecto, se sabe que este tratado es posterior a las Noctes Atticae de Aulo Gelio, pues lo que Apuleyo dice sobre los vientos en $\S \S 318-321$ lo tomó casi enteramente de 2.22. El problema es que tampoco existe acuerdo entre los especialistas sobre la datación de la obra de Gelio, si anterior al 158 o posterior al 176, o entre ambas fechas. No obstante, algunos de sus últimos editores son partidarios de una fecha más bien alta, en torno al $146^{4}$, lo cual vendría a confirmar que estamos ante una obra de juventud -habida cuenta de que nuestro autor nació sobre el 125-, compues-

\footnotetext{
${ }^{1}$ Aunque hoy se admite unánimemente que el original es el tratado griego y que el De mundo es una traducción o versión, en épocas pasadas hubo autores que postularon lo contrario, que el original era el texto latino, entre ellos Stahr 1834 y Adam 1861. Sobre esto, $c f$. Reale - Bos 1995² pp.374-375 y 378.

2 Sobre esta cuestión remitimos a los trabajos siguientes: Axelson 1952; Bajoni 1994; Barra 1966; Regen 1971; Marchetta 1991; Moreschini 1978, en particular el capítulo «Il De Platone et eius dogmate e il De mundo», pp.51-132. Las dudas sobre su autenticidad se plantearon en particular en los siglos XIX y XX, a causa de supuestos errores de interpretación del original griego y por diferencias en el empleo de las cláusulas prosódicas entre el De mundo y el De Platone, por un lado, y el resto de sus obras filosóficas y no filosóficas, por otro. A favor de su autenticidad tenemos el hecho de que San Agustín, que cita un fragmento del cap. 34 del De mundo, dice claramente que es obra del Madaurense: quae uno loco Apuleius breuiter stringit in eo libello, quem de mundo scripsit (Ciu.8.12); asimismo en los códices B, M y V, una subscriptio colocada entre el De Platone y el De mundo atribuye los dos tratados a Apuleyo. Además, el considerarla obra de un autor posterior, de en torno al siglo IV, plantea más problemas de los que resuelve. Admitida su autenticidad, sobre los motivos que llevaron a Apuleyo a traducir el Peri kosmou, descartado que pueda tratarse de un mero ejercicio escolar (dado que tampoco es tanta la calidad literaria del original griego como para proponerlo de modelo de un ejercicio literario), quizás la razón última sea que el autor latino encontró en el tratado griego una imagen

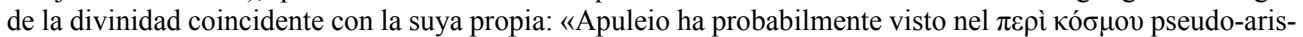
totelico un'opera che, per alcuni lati, si acostaba alle sue concezioni e alle sue credenze, e per questo motivo la ha tradotta» (Cf. Moreschini 1978, p.132).

${ }^{3}$ Otro curioso punto de coincidencia entre ambas obras, y que hablaría a favor de una composición cercana en el tiempo la una de la otra, es que ambas llevan como dedicatario a un tal Faustino, Faustine fili (cf. Plat.2.1.219 y Mund.285), que pocos investigadores creen que sea un auténtico hijo del Madaurense.

${ }^{4} C f$. Beaujeu 2002², p.XXXIII y Marcos Casquero - Domínguez García 2006, pp.20-22.
} 
ta por la misma época o poco después de su viaje de estudios a Atenas, el cual sitúa Rohde entre 143 y $151^{5}$.

Asimismo, el tema del tratado y la alusión concreta a los terremotos ${ }^{6}$, de la que aquí nos ocuparemos, es demostrativa del interés de Apuleyo por eso que podríamos llamar genéricamente las «ciencias de la naturaleza»o, en denominación latina, las naturales quaestiones, algo confirmado por noticias esporádicas que nos hablan de un cierto número de obras apuleyanas de temática «científica», como un tratado sobre los peces (Apol.38.2), donde se estudiarían ante todo cuestiones relativas a sus distintos modos de reproducción ${ }^{7}$; o las alusiones que encontramos en Juan Lido (Mens.4.116.2-3; Ost.4 y 44, entre otros) a un Apuleyo que escribió sobre cuestiones astronómicas 8 ; o, en fin, la posibilidad de que nuestro autor pudiera haber escrito un tratado de agricultura, apuntada por parte de la crítica a partir del hecho de que su nombre aparezca citado en veintiuna ocasiones en el tratado griego denominado $\mathrm{Ge}$ oponica, que data de mediados del siglo $\mathrm{X}$, aunque en esencia coincide con las Пepì

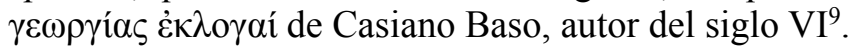

\section{SOBRE LA NATURALEZA Y TIPOLOGÍA DE LOS TERREMOTOS SEGÚN APULEYO}

En fin, pasando al que es nuestro objeto de estudio, la alusión a los terremotos se contiene en Mund.18.329-332. Después de haber estado hablando en el cap. 17 de que la tierra abunda en su interior en exhalaciones y fuego (tellus [...] spiritu et igni fecunda est) (326.13-14) ${ }^{10}$, a comienzos del cap. 18 explica que tales exhalaciones

\footnotetext{
${ }^{5}$ Cf. Moreschini 1978, p.12, quien cita a Rohde 1885. Sobre esto $c f$. también Barra 1960-1961, p.77.

${ }^{6}$ Aunque es cierto que Apuleyo se ocupó de los terremotos porque en el Peri kosmou se aludía a ellos, también es cierto que podía haber pasado por alto el tema de no haberle interesado. A este respecto, como ya ha puesto de relieve la crítica, el siglo II d. C. registra un interés notable en las fuentes literarias por el tema de los seísmos, de lo cual es demostrativo, entre otras cosas, que el propio Plutarco compusiera un tratado sobre el tema hoy perdido ( $c f$. Traina 1989, p.111).

${ }^{7}$ Et memento de solis piscibus haec uolumina a me conscripta, qui eorum coitu progignantur (Apol.38.43.9).

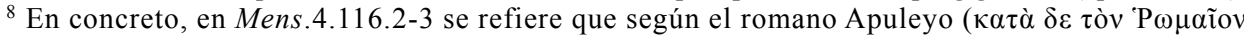
A $\pi$ ov $\lambda$ í Apuleyo escribe que en la época de Claudio se vieron tres soles y otras tantas lunas en el consulado de Gayo Fannio y Cneo Domicio, y que esto era una señal de que los galos y los sármatas habrían devastado el territorio romano; en Ost.44 se recuerda lo que, según Apuleyo, aconteció a Marcia, la esposa de Catón el Joven, quien, estando embarazada, fue alcanzada por un rayo del tipo denominado «resplandeciente» que, aunque acabó con el feto, a ella la dejó indemne. Estas referencias implicarían que Lido estaría utilizando un manual de astronomía, aunque algún autor sugiere que se trataría más bien de una recopilación de Mirabilia. Sobre esto, $c f$. Domenici - Maderna 2007, p.140, n.31.

${ }^{9}$ Cf. Rodgers 1979, p.197. Rodgers no es muy partidario de creer que el Madaurense fuera autor de un tratado de agricultura propiamente dicho, sino de un texto de originalidad muy relativa, donde se combinaran a la vez cuestiones científicas y mágicas ( $c f$. p.199); e incluso sugiere que tal tratado, dada la fama de mago que alcanzó Apuleyo en la Antigüedad tardía, bien se le pudo atribuir espuriamente (cf. p.203).

${ }^{10} \mathrm{El}$ texto latino que reproducimos es el de la edición de Beaujeu de sus opuscula. Hemos tenido también en cuenta la edición de Moreschini 1991.
} 
naturales, al desplazarse por las concavidades del interior de la tierra, golpean la parte compacta de la misma: Saepe accidit ut natiui spiritus, per terrae concauas partes errantes, concuterent solida terrarum, [...] (329.1-3).

Ahora bien, cuando tales exhalaciones golpean con más fuerza y, sobre todo, al tratar de pasar por lugares más estrechos y no encontrar una salida, acaban produciendo los movimientos telúricos: saepius ut spiritus, crescente uiolentia et insinuantes se telluris angustiis nec inuenientes exitum, terram mouerent (329.3-330.5).

Esta breve explicación del modo como actúan tales emanaciones o efluvios propios del interior de la tierra vincula claramente la causa de los terremotos con uno de los cuatro elementos de la naturaleza, el aire, sólo que con el aire contenido en las concavidades terrestres.

De otro lado, como inciso, digamos que Apuleyo no utiliza un término específico para designar los seísmos. Así en 331.14, para referirse a los ostae, un tipo de seísmo, emplea el término genérico motus, 'movimiento' (sobreentendiendo, sin duda, terrarum). Asimismo, en 34.364.20, donde vuelve a aludir a los efectos destructivos de tales fenómenos naturales, emplea la expresión tremor terrarum, 'temblor de tierra' (cf. immodicis tremoribus terrarum dissiluisse humum).

A continuación, Apuleyo propone una clasificación de los terremotos (horum motuum tam uaria nomina quam diuersi $<\ldots>$ ) $(330.5-6)$, distinguiendo hasta siete tipos de seísmos, designados todos ellos con nombres griegos:

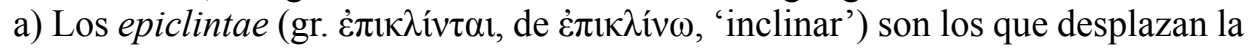
tierra hacia un lado, oblicuamente y en ángulo agudo: Namque obliquis lateribus proxima quaeque iactantes et acutis angulis mobiles epiclintae graece appellantur; [...] (330.6-8).

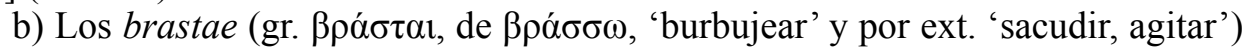
son los que hacen elevarse verticalmente el suelo lanzando al aire los objetos y haciendo que éstos vuelvan a caer en ángulo recto: sed qui subsiliunt, excutientes onera et recuperantes directis angulis, brastae uocitantur; [...] (330.8-9).

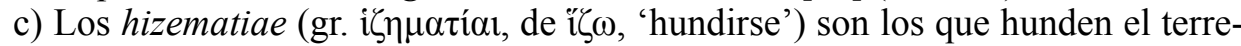
no y, por tanto, parecen ocultarlo: illi, qui abstrudere uidentur, hizematiae dicti [s]; [...] (330.9-331.10).

Respecto a este tipo concreto de terremoto, algunos editores, como Scaligero (Leiden, 1600), Thomas (Leipzig, 1908) y Moreschini (Leipzig, 1991), prefieren la

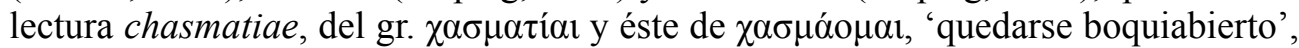
'estar entreabierto', por lo que aludiría a un tipo de terremoto que produce grietas en el suelo ${ }^{11}$.

d) Los rhectae (gr. $\dot{\eta} \tilde{\kappa} \tau \alpha$, de $\dot{\rho} \eta ́ \gamma v v \mu 1$, 'romper, desgarrar') son los que desgarran y entreabren la tierra. Añade el autor que, como consecuencia de la acción de este tipo de terremotos, a veces la tierra deja escapar vapores, escupe piedras y lodo; a veces surgen manantiales, dándose así curso a ríos recién formados:

\footnotetext{
${ }^{11}$ He aquí el texto correspondiente según la edición de Moreschini 1991: illi, qui abstrudere uidentur, chasmatiae dicti[s].
} 
quorum impulsu dissilit tellus, r(h)ectae sunt nominati. His passionibus contingit ut quaedam terrae exspirent halitus, aliae uomant saxa, nonnullae caenum; sunt quae fontes pariunt insolentibus locis, peregrinorum fluminum sulcantes uias (331.10-14).

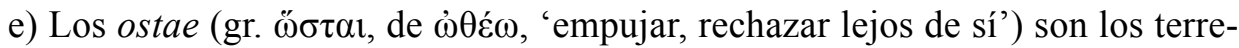
motos que agitan el suelo una sola vez: ostae sunt motus, quibus < semel> solum quatitur; $[\ldots](331.14-15)$.

f) Los palmatiae (gr. $\pi \alpha \lambda \mu \alpha \tau i ́ \alpha$, de $\pi \alpha ́ \lambda \lambda \omega$, 'agitar, blandir') son los que, a pesar de sus sacudidas, las cosas no se inclinan sino que conservan su verticalidad: palmatiae uero appellantur, quorum pauitatione illa quae trepidant sine inclinationis periculo nutabunt, cum directi tamen rigoris statum retinent (331.15-17).

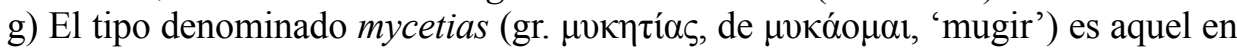
el que junto a la sacudida se oye una especie de mugido o gemido, si bien Apuleyo el primer rasgo que destaca de éste es el olor repugnante que se percibe cuando se ha producido. Nuestro autor explica que el mugido o gemido característico de este tipo de seísmo es producido por las exhalaciones que, incapaces de mover la tierra, encuentran una abertura y escapan por ella: Mycetias uocatur taetri odoris inquietudo terrena. Audiuntur mugitus, interioribus gemitibus expressis, cum spiritus inualidus ad terram mouendam per aperta telluris inuentis itineribus progreditur (331.17-332.4).

En esta clasificación de los seísmos Apuleyo depende por completo del texto griego original, como vamos a ver a continuación ${ }^{12}$. Digamos de entrada que dicha clasificación se incluye en el capítulo $4^{\circ}$ del Peri kosmou, el dedicado a los fenómenos principales que se producen en la zona sublunar, entre los parágrafos 395b.36 a 396a.16.

En el Peri kosmou ${ }^{13}$, del primer tipo de terremoto (395b.36-396a.2), los llama-

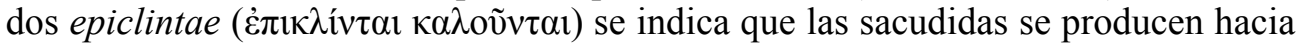

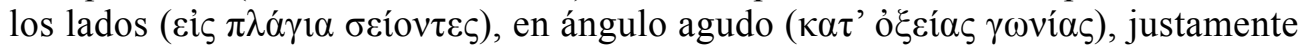
como traduce, casi literalmente, Apuleyo.

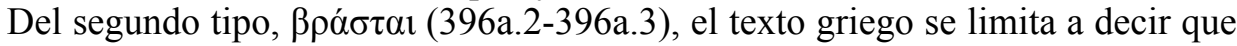
son los que lanzan de abajo hacia arriba y de arriba hacia abajo (őv

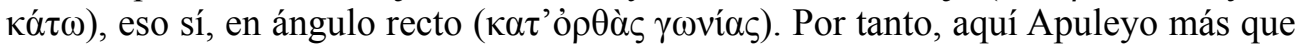
traducir lo que hace es parafrasear el texto griego para hacerlo más claro.

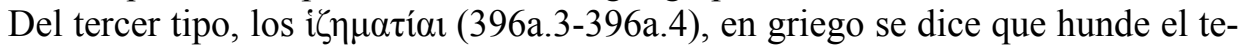

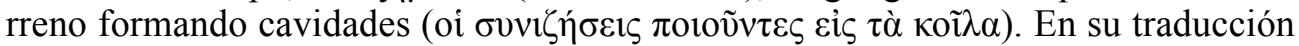
Apuleyo pretende poner de relieve el efecto último de este tipo de seísmos, la desaparición del terreno a consecuencia de su hundimiento, aunque hay que reconocer que el texto griego es más claro. De otro lado, el hecho de que en la denominación de este tipo de terremotos algunos editores prefieran la lectura chasmatiae parece de-

\footnotetext{
${ }^{12}$ Respecto a la clasificación de los terremotos que presenta el Peri kosmou, he aquí la opinión de un especialista moderno en sismología: «Le Pseudo-Aristote distingue mal les effets dûs au passage des ondes et ceux infligés aux paysages, parmi lesquels il inventorie les effondrements et les fissures» (cf. Bousquet - Dufaure - Péchoux 1983, p.27). En efecto, como insistiremos después, de los siete tipos de seísmos, los dos primeros se basan en distinguir entre seísmos horizontales y verticales, mientras que el resto se fija en sus efectos o consecuencias más aparentes.

${ }^{13}$ El texto griego del Peri kosmou lo citamos según la edición de Reale - Bos ya mencionada.
} 
berse al hecho de haber tomado como nombre de los mismos el término chasmata, 'grietas', que aparece como característica del tipo siguiente.

Del cuarto tipo, el denominado rhectae ( $\dot{\rho} \tilde{\eta} \kappa \tau \alpha l ~ \kappa \alpha \lambda o v ̃ v \tau \alpha l) ~(396 a .4-396 a .5)$, el

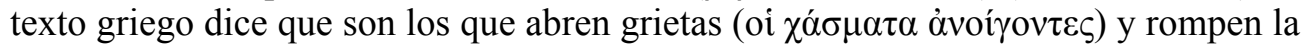

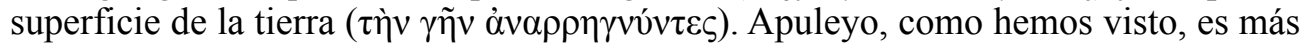
escueto, limitándose a decir que estos tipos de seísmos entreabren la tierra.

Como ya hemos visto en Apuleyo, también el texto griego, después de mencionar el cuarto tipo de terremoto, se detiene a enumerar algunas de las consecuencias de este tipo concreto de seísmo que agrieta la tierra (396a.5-396a.7). En efecto, a veces tras un terremoto se dejan escapar (del interior de la tierra) vientos (es decir, va-

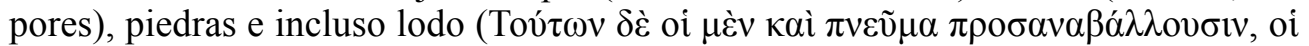

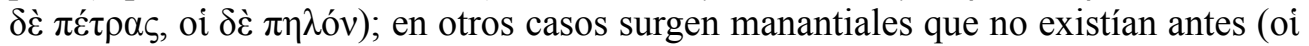

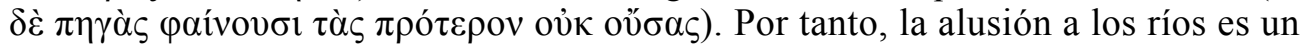
simple añadido original de Apuleyo.

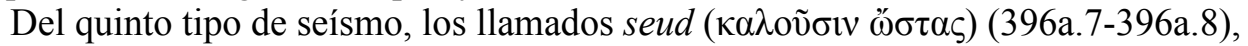
el texto griego dice que son los que producen una perturbación por medio de una

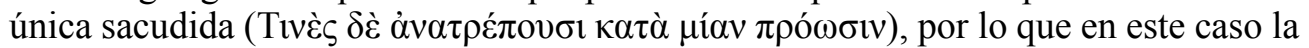
concordancia entre el griego y la versión de Apuleyo es completa.

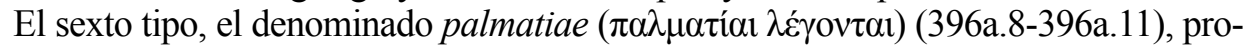
duce una especie de movimiento de vaivén (Oi $\delta \grave{\varepsilon} \alpha \dot{\alpha} \tau \alpha \pi \mathrm{t} \pi \dot{\alpha} \lambda \lambda \mathrm{ov} \tau \varepsilon \varsigma$ ) y con sus inclina-

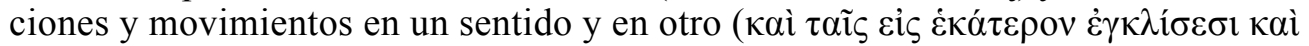

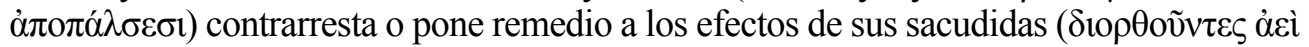

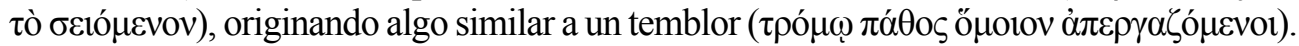
Apuleyo, obviamente, no traduce sino que explica el sentido de la frase griega.

El séptimo y último tipo, que Apuleyo denomina mycetias y que el griego llama

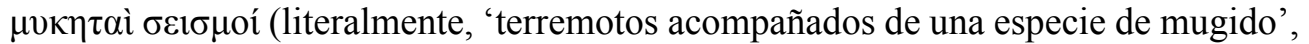
es decir, de un rumor sordo, pues $\mu v \kappa \eta \tau \alpha i ́$ deriva del verbo $\mu v \kappa \alpha ́ o \mu \alpha 1$, 'mugir') ${ }^{14}$ (396a.11-396a.12), es, según el texto griego, aquel que sacude la tierra acompañado

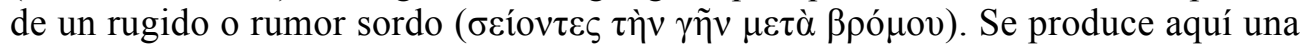
importante discrepancia entre el texto latino y el original griego, pues Apuleyo parece relacionar el nombre de este tipo de seísmo con el hecho de que produce un olor fétido. La razón de esta discrepancia podría estar más que en una confusión de Apuleyo entre $\beta \rho o ́ \mu o v ~$ y $\beta \rho \tilde{\omega} \mu о v$, de $\beta \rho \tilde{\omega} \mu о \varsigma$, , 'olor infecto',--algo raro en un autor con un dominio del griego como el suyo-, en que en el texto griego que manejó nuestro autor apareciera el segundo término, $\beta \rho \tilde{\omega} \mu \mathrm{\mu ov}$, como conjeturó $\mathrm{W}$. L. Lorimer en el aparato crítico de su edición del De mundo de $1933^{15}$.

\footnotetext{
${ }^{14}$ Según Liddell - Scott - Jones 1996, s.u. $\mu v \kappa \eta \tau i ́ \alpha \varsigma, ~ p .1152$, la forma correcta del adjetivo podría ser

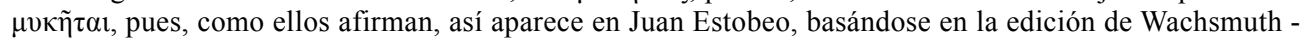
Hense 1884-1912; reimpr. 1958. Sin embargo, en la edición de Reale - Bos, que nosotros seguimos, se lee

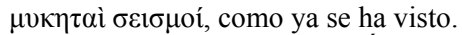

${ }^{15}$ Cf. Lorimer 1933, p.73. Éste es el editor que prácticamente ha dejado fijado el texto griego del Peri kosmou. Para los problemas textuales que plantea esta obra, $c f$. Lorimer 1924, así como, del mismo autor, 1925. De otro lado, algunos editores, como Wowerus (Hamburgo 1606), Floridus (París 1688) y Thomas (Leipzig 1908), han propuesto corregir el odoris del texto latino por rudoris, para adecuarlo al griego $\beta \rho o ́ \mu o v$.
} 
A continuación, el texto griego (396a.12-396a.16) añade que en muchas ocasiones, independientemente del terremoto, se produce una especie de mugido o rumor

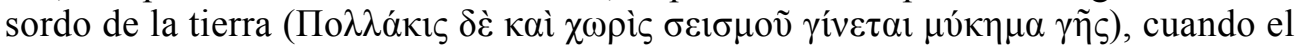

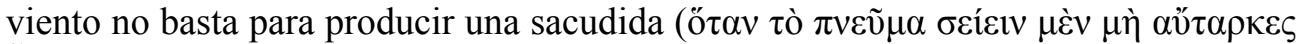
$\tilde{\tilde{n}})$, encerrado en la tierra la golpea con su fuerza impetuosa ( $\dot{\varepsilon} v \varepsilon 1 \lambda$ ov́ $\mu \varepsilon v o v \delta \dot{\varepsilon} \varepsilon \dot{\varepsilon} v \alpha \hat{v} \tau \tilde{\eta}$

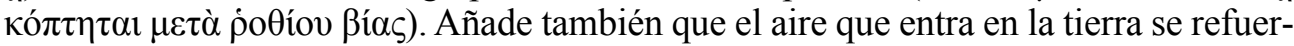

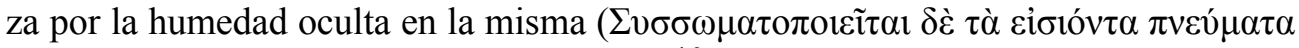

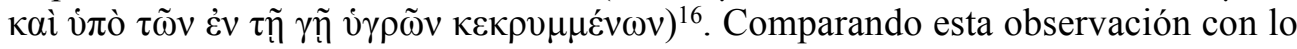
que dice Apuleyo, hay algunas discrepancias. En efecto, el autor latino entiende que ese mugido o rumor sordo se produce cuando el aire contenido en la tierra, incapaz de conmoverla, sale tras encontrar aberturas en el suelo. El texto griego, en cambio, afirma que ese rumor es el resultado del aire que golpea la tierra con una fuerza que, aunque «impetuosa», no es suficiente para producir una sacudida. Del último detalle, que con la humedad oculta en la tierra se refuerza el aire que entra en la misma, Apuleyo no dice nada, quizás porque a su juicio no añadía nada relevante.

El balance global de la comparación que acabamos de hacer entre el texto griego del Peri kosmou sobre los terremotos y la versión apuleyana del mismo es que, sin ser una traducción literal o fiel del mismo (salvo en dos casos), Apuleyo es bastante respetuoso con el texto original, cuyo sentido al menos capta bien, salvo en la descripción del séptimo tipo de seísmo, donde hay algunas discrepancias y, sobre todo, omisiones, en particular, la alusión del griego al aire que entra en la tierra -sin olvidar que la relación, errónea, entre el tipo de seísmo llamado mycetias y el olor fétido se debería, creemos nosotros, a que en el texto que él maneja apareciera la forma $\beta \rho \tilde{\omega} \mu o v-$. Otro rasgo importante de la versión apuleyana es que, frente a su costumbre habitual en otros pasajes del De mundo, en éste Apuleyo ni añade ni quita apenas partes del original, y cuando lo hace parece estar guiándose siempre por razones de claridad.

En fin, si nos fijamos bien en la clasificación de los terremotos que proponen tanto Apuleyo como el Peri kosmou, conviven dos tipologías: una, que se basa en distinguir los terremotos horizontales (epiclintae) y los verticales (brastae); mientras que la segunda se fija en sus efectos o consecuencias, dentro de la cual entran los que producen hundimientos del terreno (hizematiae) o grietas (chasmatiae), las que desgarran la superficie de la tierra (rhectae), las que producen perturbaciones por medio de una única sacudida (ostae), las que producen una suerte de movimiento de vaivén o algo similar a un temblor (palmatiae) y las que producen una especie de rugido (mycetias).

\section{LAS TEORÍAS ANTIGUAS SOBRE LA NATURALEZA DE LOS TERREMOTOS Y SU TIPOLOGÍA HASTA LA ÉPOCA DE APULEYO}

El mundo antiguo se acercó a los terremotos desde dos ópticas en principio opuestas, la mágico-religiosa, que veía en los movimientos sísmicos una señal (portentum, ostentum) de la ira divina contra los hombres por algún tipo de transgresión moral o religiosa, y la científico-naturalista, que trataba de explicar los fenómenos

${ }^{16}$ Seguimos aquí la traducción de Reale - Bos $1995^{2}$, p.205. 
telúricos acudiendo a causas naturales, sin ninguna clase de intervención divina, en muchos casos para mitigar el miedo que un terremoto produce en el hombre: esto justifica que un moralista como Séneca sea el autor del tratado más amplio sobre los terremotos que nos ha legado el mundo antiguo. Por razones obvias, en nuestro trabajo nos centraremos en esta segunda perspectiva ${ }^{17}$.

\subsection{ARISTÓTELES}

De entrada, la teoría enunciada en el De mundo según la cual los terremotos son debidos a las masas de aire que encierra la tierra, por lo que se trataría de un fenómeno meteorológico más, es de raíz aristotélica, como el propio tratado del Peri kosmou ${ }^{18}$. Aristóteles habla de los terremotos en Mete.2.7-8 (365a.14-369a.9), tras dedicar los capítulos 4,5 y 6 a hablar de los vientos. Esto se explica porque, como dice el Estagirita, la causa de los movimientos sísmicos es próxima a este tipo de meteoro (365a.15) ${ }^{19}$.

${ }^{17}$ Desde la perspectiva mágico-religiosa, el dios de los terremotos en el mundo griego era Posidón, como demuestran los epítetos homéricos غ̇voбíx $\theta \omega v$, 'que sacude la tierra' (Il.7.445;8.208;11.751, etc.; Od.1.74;5.282;7.35,etc.)

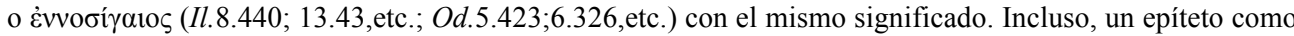

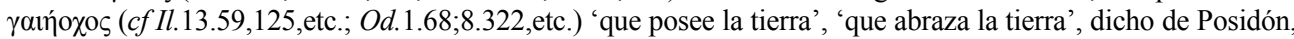
incidía en su carácter de responsable divino de los movimientos sísmicos. Por eso mismo parece que originaria-

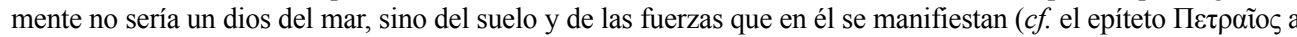
él atribuido que aparece en los Escolios a PIND.P.4.246). Asimismo, si el dios provoca los seísmos también pue-

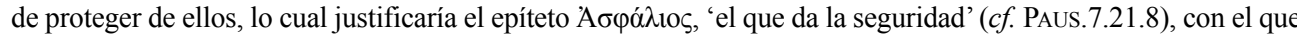
también se le conocía. Precisamente a un Posidón Asphálios se le rendía culto en Laconia por ser una zona especialmente sísmica. A esta interpretación religiosa habría que adscribir también la posibilidad de que algunos hombres sean capaces de pronosticarlos, como se supone que hicieron Anaximandro y Ferecides ( $c f$. Cic.Div.1.50.112 y Plin.Nat.2.79.191, si bien el Arpinate no los considera adivinos sino científicos). En el ámbito de la literatura antigua, fue la historiografía la que mostró más interés por la descripción de los terremotos, considerados normalmente como prodigios o signos premonitorios y como tales vinculados con acontecimientos militares y políticos. Así, Heródoto en 6.98 refiere el terremoto que sacudió Delos «la primera y la última vez» hasta la época del autor, que él interpreta como portento provocado por Apolo para avisar a los hombres de las desgracias que se avecinaban. En Tito Livio es tan frecuente la referencia a terremotos (acompañados de la alusión a otros prodigios) que gracias a él conocemos bien la sismicidad de Italia de época republicana. Los terremotos también fueron usados en el contexto de la lucha entre paganismo y cristianismo, de modo que, por un lado, los cristianos atribuyeron todos los seísmos de los años 350 al 370 a la impiedad de Juliano el Apóstata; por otro, Maximino Daya, en su rescripto contra los cristianos (cf. Eusebio de Cesarea, HE.9.7.3-14), les acusaba de subvertir el orden natural provocando pestilencias y terremotos. En fin, un autor cristiano, Filastrio, obispo de Brescia, que vivió en el siglo IV, convencido de que los terremotos eran expresión de la voluntad divina, en su Liber de haeresibus catalogó como herejía la creencia de que los terremotos se debían a la intervención natural de los elementos. Sobre la interpretación mágico-religiosa de los seísmos, $c f$.. Traina 1989, en particular pp.106109; Helly 1989, sobre todo pp.5, 80-83 y Guidoboni 1989, p.178.

${ }^{18}$ Respecto a las fuentes clásicas sobre las causas y naturaleza de los terremotos, $c f$. Châtelain 1909; Capelle 1924; Helly 1983; Marmo 1989 y Waldherr 1997.

${ }^{19}$ En realidad, el responsable de que en la Antigüedad la sismología fuera un capítulo de la meteorología fue Anaxágoras, aunque las explicaciones dadas fueran diferentes entre ambos. En Aristóteles, para entender su teoría sobre los terremotos, es preciso comprender ciertos principios fundamentales de su física. Así, para él los cuerpos del mundo sublunar y terrestre están constituidos por los cuatro elementos esenciales, la tierra, el agua, el aire y el fuego, entre los cuales no existen fronteras infranqueables, de forma que pueden mezclarse y penetrarse los unos a los otros. Sobre esto, $c f$. Helly 1983, p.64. 
Comienza Aristóteles su exposición ${ }^{20}$ resumiendo las tres teorías conocidas hasta su época para explicar el origen de este tipo de fenómeno, cuyos artífices eran Anaxágoras de Clazómenas, Anaxímenes de Mileto y Demócrito de Abdera (365a.16-19).

Según Anaxágoras, el origen de los terremotos estaría en el aire $\operatorname{seco}^{21}$ que, contenido en las partes bajas y huecas de la tierra, tiene tendencia a elevarse y a mover a ésta, al quedar la parte alta de la tierra apelmazada por la lluvia ${ }^{22}$ (365a.19-23).

La respuesta de Aristóteles a esta teoría es contundente: se trata de un conjunto de ideas simplistas e ingenuas, que en realidad no explican la causa verdadera de este tipo de fenómeno, pues éste no se produce en cualquier región o época (365a.25-35).

Por su parte, según Demócrito, la tierra, que está llena de agua, es movida por ésta cuando recibe un aporte extra proveniente de la lluvia. Según el resumen que hace Aristóteles, cuando las cavidades subterráneas de la tierra se colman con un exceso de agua, ésta, al abrirse paso por la fuerza, provoca la sacudida sísmica; asimismo, cuando la tierra está seca y atrae agua de los lugares llenos a los vacíos, el agua en su movimiento de una zona a otra, al irrumpir, provoca también el seísmo (365b.1-6).

De otro lado, para Anaxímenes, los terremotos se producen cuando la tierra se seca y se empapa, resquebrajándose y desmoronándose. A saber, en las épocas de sequía, la tierra se resquebraja al secarse, mientras que en las de lluvia, al empaparse excesivamente por ésta, se desmorona. Por eso los seísmos sólo se producen en épocas de fuerte sequía o muy lluviosas (365b.6-12).

Respecto a esta teoría, Aristóteles afirma que su validez se pone en duda por varios motivos: a) de ser como dice Anaxímenes, veríamos la tierra hundiéndose por muchos sitios; b) asimismo, vemos que los terremotos se producen muchas veces en lugares que no difieren de otros, donde son menos frecuentes, por sus condiciones de sequedad o humedad; c) si los terremotos fueran el resultado del proceso de hundimiento de la tierra, éstos tenderían a ser cada vez menos frecuentes, pues tras un hundimiento, el terreno tiende a asentarse de nuevo, con lo que dejaría de ser inestable (365b.12-20).

Por su parte, la teoría aristotélica de los terremotos toma como punto de partida la existencia de dos tipos de exhalaciones, una húmeda y otra seca ${ }^{23}$ : en efecto, aun-

\footnotetext{
${ }^{20}$ Para la exposición de Aristóteles sobre los terremotos nos ha sido de gran utilidad la traducción de Candel 1996. De otro lado, no compartimos la opinión de Helly 1983, p.64 de que la exposición aristotélica sea la más completa de la Antigüedad sobre los terremotos y sus causas. Como se verá después, la de Séneca es mucho más extensa no sólo en longitud sino en información sobre las causas. A la de Aristóteles, en cambio, le cabe el honor de ser la que más espacio dedica al comportamiento aparente de los movimientos sísmicos.

${ }^{21}$ En realidad, el término usado por Aristóteles es aither, no aer, que el traductor al que seguimos, Candel 1996, p.343, n. 369, interpreta como 'aire seco'.

22 Según lo que aquí nos dice Aristóteles, Anaxágoras concebía la esfera terrestre dividida en una parte alta y otra baja, siendo la primera aquella sobre la que habitamos (365a.23-25).

${ }^{23}$ La combinación de estos dos tipos de exhalaciones constituye el aire. Será la interacción entre estas dos formas de exhalación, causada por el roce que las esferas celestes ejercen sobre el aire, de donde resultan todos los meteoros, así como los fenómenos que se producen en la hidrosfera y prácticamente toda la geodinámica (cf. Candel 1996, p.234). Esto supone reconocer que todos los fenómenos del cosmos, hasta los más simples y diversos, arrancan del movimiento de las estrellas, el considerado más simple y regular, y contra esta teoría nada pudieron durante casi veinte siglos la observación de un cierto número de anomalías, procedentes de la experiencia, que contradecían tal aserto teórico.
} 
que la tierra es seca de por sí, gracias a la lluvia contiene mucha humedad; de esta forma, cuando es calentada por el sol y por el fuego que contiene en su interior, se genera una gran cantidad de viento que unas veces sopla hacia fuera, otras hacia dentro y en otros casos una parte sopla hacia fuera y otra hacia dentro ${ }^{24}$ (365b.21-28).

Asimismo, tras analizar la naturaleza del viento, según la cual el más violento es el que se desplaza con más rapidez y el más fino es el que llega más lejos, pues es el que más fácilmente puede atravesarlo todo, se concluye que de entre todos los cuerpos éste será el más capaz de mover las cosas. Por eso, según Aristóteles, será el viento, no el agua ni la tierra, la causa de los movimientos sísmicos, cuando por azar un soplo externo fluye hacia el interior de la tierra (365b.29-366a.5).

De aquí deduce Aristóteles que la mayoría de los terremotos y los más importantes se producirán durante los periodos de calma: en efecto, al ser el soplo de aire continuo, hemos de entender que una vez que cesa el flujo de viento, todo el impulso inicial se lanza de una vez hacia dentro o hacia fuera (366a.5-8).

Sin embargo, no descarta el Estagirita que puedan producirse seísmos cuando sopla el viento, siempre que haya varios soplando a la vez y uno de ellos se precipite hacia el interior de la tierra. Pero al encontrarse su fuerza dividida entre varios vientos, estos seísmos serán de menor magnitud que cuando es un único viento el que los produce (366a.8-12).

Asimismo, la mayoría de los terremotos y los más importantes se producen de noche, y los que tienen lugar de día se producen al mediodía, dado que en ambos casos es cuando reina más calma. En efecto, en el caso de la noche reina una gran calma por la ausencia de sol; y el mediodía es el momento de mayor calma de todo el día, porque entonces es cuando el sol tiene mayor poder y puede así confinar las exhalaciones en el interior de la tierra (366a.13-18).

Siguiendo con su detallada casuística de los terremotos, los más fuertes son los que se producen en lugares donde el mar tiene muchas corrientes -en tales lugares el mar parece filtrarse bajo tierra- o el terreno es poroso o cavernoso (citando como ejemplo regiones como el Helesponto, Sicilia o Eubea). La razón está en la estrechez del espacio en el interior de la tierra de estas regiones: cuando surge un viento violento, éste encuentra su paso obstaculizado por la gran masa de agua del mar que le obliga a volver al interior de la tierra; en el caso de los terrenos porosos, es mayor la cantidad de viento que entra, por lo que se estremece más (366a.24-366b.2).

Analiza después Aristóteles las épocas del año más favorables a los terremotos, siendo éstas la primavera y el otoño, y en épocas de lluvia y sequía, precisamente cuando más vientos hay ${ }^{25}$; en cambio, añade, el verano y el invierno, el primero por el

\footnotetext{
${ }^{24}$ Es decir, la sustancia natural del viento sería el aire seco, el cual constituye propiamente el pneuma que está en la base de la teoría aristotélica acerca de los terremotos. Sobre esto, $c f$. Marmo 1989, p.174 y Helly 1989, ibid.

${ }^{25}$ Es interesante la observación que hacen respecto a las épocas favorables para los terremotos Bousquet Dufaure - Péchoux 1983, p.35, donde Aristóteles, y con él otros autores antiguos, confunde la causa y el efecto: en primavera y otoño, cuando más fuertes suelen ser las lluvias en el área mediterránea, los efectos de un deslizamiento de tierra tras un terremoto pueden ser más catastróficos.
} 
excesivo calor y el segundo por el frío, son épocas poco ventosas, y por ello poco propicias a los seísmos. Las épocas de sequía son ventosas, pues en ellas predomina la exhalación seca sobre la húmeda; en épocas de lluvia, en cambio, se producen más flujos de aire en el interior de la tierra, que al quedar encerrados en un espacio más estrecho y comprimidos en él, por encontrarse las cavidades de la tierra más llenas de agua, el viento al moverse golpea y sacude la tierra con mayor fuerza (366b.2-14). Luego emplea la imagen del aire encerrado en nuestro cuerpo, que produce estremecimientos y palpitaciones, para ilustrar mejor lo que sucede en el interior de la tierra ${ }^{26}$. Lo que ocurre con el aire en el interior de los cuerpos de los animales (en concreto, con los ataques de rigidez y los espasmos), demuestra su fuerza y que éste no necesita de grandes masas (como cuando está en el exterior) para ejercer sus efectos (366b.15-30).

Para ejemplificar lo que acaba de decir, recuerda lo sucedido en dos seísmos recientes, los de Heraclea del Ponto y de la isla de Hiera, lugares ambos en donde, según nuestro autor, un seísmo producido en un lugar concreto no se detuvo hasta que el viento que lo producía no salió del interior de la tierra con apariencia de huracán (366b.30-367a.11).

Se detiene luego Aristóteles a dar otras pruebas que demuestran que los vientos soplan bajo tierra, algunas de las cuales son signos anunciadores de terremotos.

Entre ellas, uno de los primeros signos que explica es el oscurecimiento del sol, aun cuando no haya nubes, así como la calma y fuertes heladas antes de seísmos importantes. En todos los casos, la explicación tiene que ver, según Aristóteles, con el hecho de que el viento se pierda bajo tierra. En los momentos de calma, cuando el aire se introduce en el interior de la tierra, si éste no se escinde sino que se concentra en un único lugar, la sacudida sísmica será más fuerte. Respecto al frío, éste se explica porque ese mismo aire o viento, que por sí mismo es cálido, al desaparecer en la tierra se condensa en forma de humedad, originando el frío en los lugares donde tiene lugar el fenómeno (367a.20-367b.7).

El otro signo que se analiza es la tenue nube que se extiende a lo largo, bien de día, bien poco antes del ocaso, con el cielo despejado, y que es otro signo anunciador de seísmos, y que se produce cuando el viento se extingue al desplazarse al interior de la tierra (367b.7-12).

Este mismo desplazamiento del viento al interior de la tierra explicaría que se produzcan seísmos durante los eclipses de luna. En efecto, cuando ya está cercana la interposición entre la luna y el sol y aún no han desaparecido del aire la luz y el calor del sol, pero ya se están extinguiendo, se produce una calma, cuando, como se ha apuntado, el viento desaparece bajo tierra y esto provoca el terremoto antes del eclipse (367b.19-25).

De otro lado, para explicar por qué los terremotos de gran magnitud no cesan inmediatamente del todo, sino que pueden durar en el tiempo, eso sí, con menor intensidad, durante cuarenta días e incluso, a veces, a lo largo de uno o dos años, Aristóte-

\footnotetext{
${ }^{26}$ La comparación entre lo que sucede en el interior de la tierra y en el interior del cuerpo es posible porque también la medicina hipocrática, la que conoce Aristóteles, manejaba como concepto fundamental el de pneuma o 'soplo', en el que se basaba la vida y la muerte. Sobre esto, $c f$. Helly 1983, p.68.
} 
les afirma que eso se debe a la cantidad de viento que produce el seísmo y a la configuración del terreno por el que pasa. En efecto, si la cantidad de viento es grande y no puede liberarse de golpe, sino que queda atrapado en las concavidades del terreno, mientras no se agote toda la materia que provocó el seísmo se seguirán produciendo sacudidas cada vez más suaves (367b.32-368a.13).

A menudo se producen ruidos bajo tierra antes de un seísmo e incluso sin que éste llegue a producirse. El responsable es también el viento. En efecto, igual que el aire golpeado emite toda clase de ruidos, lo mismo sucede cuando es él el que golpea. El ruido es tan sutil que puede pasar a través de los objetos sólidos con más facilidad que el propio viento. Debido a ello, el ruido se adelanta al propio terremoto, y cuando el azote del viento contra la tierra es demasiado débil como para producir un seísmo, como no obstante choca contra masas compactas y de múltiples formas, es tal el ruido que se podría decir que la tierra ruge (368a.14-25).

En su repaso exhaustivo por toda la fenomenología de un seísmo, se detiene Aristóteles en un hecho habitual: la aparición de agua a borbotones tras producirse una sacudida sísmica. Evidentemente, no ha sido el agua la causa del seísmo, sino el viento, tanto si sopla desde la superficie como si lo hace desde el interior; incluso alguien podría pensar en la tierra como causa, pues tras un seísmo es frecuente que ésta, como el agua, se dé la vuelta tras la sacudida. Pero, como dice nuestro autor, ni el agua ni la tierra, en tanto que materia, son causas, sólo el viento puede serlo (368a.26-34).

En 368a.34-368b.12, Aristóteles trata de explicar un fenómeno tan complejo para los antiguos como los terremotos que tienen su epicentro en el fondo marino, provocando el fenómeno conocido como tsunami. En efecto, según nuestro autor, cuando se produce una ola a la vez que un seísmo, la causa está en el choque de vientos contrarios: cuando el viento que golpea la tierra no puede apartar del todo el agua del mar que arrastra otro viento, se produce una acumulación de agua que se concentra en un punto concreto, la cual, al cesar el primer viento, avanza sobre la tierra empujada por el segundo viento, contra la cual rompe, produciendo la inevitable inundación.

Otra característica que presentan los seísmos, según Aristóteles, es que se localizan en puntos muy concretos de la tierra, igual que las sequías y las lluvias torrenciales. El motivo es que en los terremotos las exhalaciones del lugar donde se producen y las de las inmediaciones convergen en un único punto, pues todas ellas proceden de la tierra. En cambio, los vientos, que dependen de la exhalación aérea, la cual se va produciendo conforme el sol va recorriendo su órbita, no pueden concentrarse en un único punto localizado (368b.13-22).

Si en un seísmo interviene una gran cantidad de viento sacude la tierra a lo ancho, como si fuera un estremecimiento; pero a veces se parece más a una palpitación, sacudiendo la tierra de abajo arriba. Este tipo de seísmo es poco frecuente porque de esa manera no se acumula mucho empuje. En los lugares donde se produce es normal que aflore gran cantidad de piedras. Se añade a continuación algunos ejemplos de seísmos de este tipo, como los que destruyeron las inmediaciones del Sípilo (monte de Lidia) (368b.23-32). 
Con esta modalidad poco habitual de terremotos termina la exhaustiva exposición aristotélica sobre las causas y comportamiento aparente de los terremotos, fenómeno éste vinculado, según el Estagirita, con los vientos, tanto los que la tierra contiene en su interior como aquellos que circunstancialmente entren dentro desde el exterior. También es interesante subrayar su preocupación por precisar las condiciones más favorables para que se produzcan grandes seísmos, a saber, durante las calmas; de noche o al mediodía; donde el mar tiene muchas corrientes o el terreno es poroso o cavernoso; en las épocas del año lluviosas y de sequía, por ser las más ventosas; durante los eclipses de luna. En todos los casos los seísmos son debidos a la particular física del viento, sobre todo cuando se desplaza por las cavidades y anfractuosidades del interior de la tierra.

Esta teoría, que llegó a ser la más canónica en la literatura científica antigua, no entra en lo que es la principal aportación del De mundo / Peri kosmou, una detallada tipología de los seísmos, aunque ya de la propia exposición aristotélica podría extraerse con facilidad una cierta clasificación: según su grado de intensidad; cuando hay ruido pero sin sacudida; los que son como un estremecimiento por producirse la sacudida a lo ancho y los que se parecen a una palpitación por verse la tierra sacudida de abajo $\operatorname{arriba}^{27}$ (estos dos corresponderían a los dos primeros tipos de terremotos que distinguen Apuleyo y el Peri kosmou). La falta de una tipología se debió sin duda a que Aristóteles abordó el fenómeno como un todo unitario, por eso sólo se fija en sus causas, naturaleza y comportamiento aparente.

\subsection{LUCRECIO}

Entre los autores latinos de tratados «científicos», Lucrecio se ocupó de los terremotos en su libro $6^{028}$, el dedicado, entre otros, a gran número de fenómenos atmosféricos, entre los versos 535 y $607^{29}$. Según este autor, los terremotos se producen por el colapso o derrumbe de grandes masas en el interior de la tierra al hundirse las grandes cavernas que ésta guarda en su seno (vv. 543-545). Previamente ha dicho que la tierra, tanto en su superficie como en sus profundidades, está llena de cavernas ventosas (uentosis undique plenam / speluncis) con muchos lagos y lagunas.

\footnotetext{
${ }^{27}$ Cuando Estrabón dice en 4.1.7.16-18 que un tipo de terremoto que Aristóteles denominaba brastai-el que sacude la tierra en vertical- hacía aflorar piedras a la superficie, demuestra lo que nosotros estamos suponiendo aquí, que, aunque el Estagirita no elaborara una tipología de seísmos, en su obra era fácil distinguir o rastrear algunos tipos básicos, como hace Estrabón.

${ }^{28}$ Para el texto latino y la traducción española nos hemos servido de Valentí Fiol 1976.

${ }^{29}$ El objetivo fundamental de su exposición sobre los terremotos es, como declara al comienzo del libro $6^{\circ}$, disipar el temor y tinieblas del espíritu (terrorem animi tenebrasque, 39$)$ mediante la contemplación de la naturaleza y la ciencia (naturae species ratioque, 41 ), es decir, recurrir a la razón para combatir el miedo que provoca al hombre un fenómeno que, como en el caso de los truenos, los relámpagos o los rayos (otros de los temas tratados en este libro $6^{\circ}$ ), a menudo se atribuía a los dioses. Sobre los terremotos en Lucrecio es interesante el trabajo de Squillante 1992. Para esta autora, la teoría lucreciana sobre los terremotos remontaría al estoico Posidonio ( $c f$. p.99, n. 5) y se basa en el principio epicúreo «dello stretto collegamento che vincola armonicamente sostanze differenti per cui ad un'azione pur minima corresponde un fenomeno di propagazione che a volte può riguardare sezioni molto ampie del reale» (p.99).
} 
En su exposición es fácil identificar distintos tipos de terremotos, que él no designa con nombres concretos, sino que explica como diversas formas de manifestarse el fenómeno. Así, a veces, todo el aire contenido en las cavernas subterráneas se reúne y empuja sobre un punto determinado, haciendo que la tierra se incline hacia donde empuja el viento (vv. 557-560). Esto provoca la inclinación de todas las construcciones levantadas en su superficie, sobre todo las más altas. Pero cuando cesa la presión del viento, todo se endereza, recobrando su equilibrio y estabilidad.

Otro de los tipos de seísmos que podemos reconocer en la exposición de Lucrecio es cuando grandes masas de aire, procedentes de fuera o formadas en su interior, se lanzan rugiendo por las cavernas del interior de la tierra y hacen estallar su furia hacia fuera, desgarrando la tierra y abriendo en ella un gran abismo (vv. 577-584).

En fin, hay un tercer tipo que se manifiesta por una especie de estremecimiento seguido de un temblor, debido a que los vientos soplan fieramente por los entresijos de la tierra, sin llegar a estallar fuera ${ }^{30}$ (vv. 591-593).

\subsection{PLINIO EL VIEJO}

Otro de los autores latinos que se ocupa ampliamente de los seísmos es Plinio el Viejo, en Nat.2.79-84, fundamentalmente ${ }^{31}$.

Después de recordar que para los babilonios la causa de los seísmos estaba en los astros, en concreto, en los mismos a los que ellos atribuían los rayos (a saber, los planetas Saturno, Júpiter y Marte), cuando giraban con el Sol o estaban en conjunción con él, sobre todo, cerca de las cuadraturas celestes $^{32}$ (Nat.2.191.79), para él, como

${ }^{30}$ La exposición de Lucrecio termina poniendo de relieve el temor que domina al hombre a causa de los terremotos: que se hundan los techos que tienen sobre sí y que se abra bajo sus pies el suelo, al hundirse de súbito las cavernas subterráneas.

${ }^{31}$ En este caso, nos ha sido de gran utilidad Serbat - Fontán - Moure Casas et al. 1995.

${ }^{32}$ Los mejores representantes en el mundo antiguo de esta vinculación de los seísmos con los astros son Claudio Ptolomeo y Juan Lido, teniendo en ambos autores los signos zodiacales un papel determinante. Ptolomeo da en su Tetrabiblos varios ejemplos, en los cuales el anuncio de terremotos se acompaña de otros fenómenos de carácter meteorológico, por lo que se trataría de un capítulo más de eso que se llama astrometeorología (sobre esto, $c f$. Hübner 2003). Así, en Tetr.2.9.18, hablando del planeta Mercurio dice que, en relación al aire, dado que el astro es muy seco y rápido por causa de su cercanía al Sol y por la velocidad de su revolución, favorece la aparición de vientos irregulares, intensos y cambiantes, así como huracanes y terremotos, entre otros fenómenos. En Tetr.2.12.3, hablando de la constelación de Tauro, Ptolomeo afirma que, aunque en su conjunto indica la temperatura y es algo cálido, considerada en sus partes, su parte primera, especialmente la cercana a las Pléyades, favorece los terremotos, los vientos y las nieblas (para otros pronósticos, $c f$. Tetr.2.12.4 y 6). Lido resume en Ost.17-20 una serie de pronósticos extraídos de terremotos, cuando se producen coincidiendo con el tránsito de la Luna por los signos zodiacales; asimismo, en Ost.55-58 incluye el tratado sismológico de un tal Vicelio, autor por lo demás desconocido para nosotros, donde los pronósticos se obtienen al coincidir un seísmo con el paso del Sol por esos mismos signos. En ambos casos, los presagios y anuncios se sitúan en el ámbito de la apotelesmática universal -pues afectan a pueblos enteros, a reyes, generales o nobles, pero no al hombre común a título individual-, y ya no tienen que ver sólo con la meteorología, sino principalmente con la corografía astrológica, es decir, se anuncian sucesos que afectan a determinados países o regiones, sobre todo en el tratado de Vicelio. Así, en 55, si estando el Sol en Tauro se produce un terremoto en el Asia interior, una pestilencia letal se abatirá sobre los persas, sobre los etíopes que viven cerca del río Indo, sobre la costa de Asia Menor y sobre las islas Cícladas y Chipre, y las bestias de carga de estas mismas regiones morirán. 
para Aristóteles, la causa de los terremotos está en el viento, y alega como pruebas que la tierra sólo sufre sacudidas con el mar en calma y con el cielo sereno; asimismo, también después del viento, es decir, cuando éste queda encerrado en las venas y cavernas interiores de la tierra. La relación entre los seísmos y el soplo del viento la refuerza al equiparar el temblor de la tierra con el trueno en la nube, y las grietas que se producen en la tierra con el rayo (Nat.2.192.79).

Frente a Aristóteles, Plinio sí habla de temblores de distintos tipos, que provocan efectos extraños y diversos, aunque sin asignarles un nombre concreto. Así, se podría decir que establece una tipología de los seísmos según sus efectos: los hay que en un lugar derriban murallas, en otro producen profundos socavones que lo engullen todo, en otros vomitan enormes masas de material, en otros hacen brotar ríos e incluso lenguas de fuego y aguas termales; en fin, en otros casos llegan incluso a cambiar el curso de los ríos (Nat.2.193.80).

En esta suerte de clasificación sísmica, otro de los criterios, además del de los efectos que producen, es el tipo de ruido que suele preceder y acompañar a la sacudida sísmica. Así, en algunos casos se oye un sonido terrorífico, en otros una especie de murmullo, o un mugido o gritos humanos, e incluso un sonido similar al del fragor de las armas en el combate (Nat.2.193.80).

Según el tipo de material que expulsan y la forma de las galerías o cavernas que atraviesan, el sonido es más fino en un paso estrecho, ronco en los pasos curvos, retumba en los duros, bulle en los húmedos, fluctúa en los pantanosos y se embravece contra los compactos. Esto explica que a veces se produzca sonido incluso sin temblor (Nat.2.194.80).

También hay diferencia en las grietas que producen: a veces dejan ver lo absorbido, otras veces cierran sus bordes y se recubren, no dejando en el suelo ninguna huella (Nat. 2.194.80).

Plinio pasa a continuación a enumerar los lugares y las circunstancias más favorables para los terremotos, algo que toma casi en su totalidad de Aristóteles. Así, las zonas más expuestas son las marítimas, aunque también las montañosas (según testimonia por su propia experiencia). Las épocas del año más favorables son el otoño y la primavera. También es más favorable la noche que el día, aunque las sacudidas más fuertes se producen en torno al amanecer y al atardecer, sin olvidar el mediodía. También con los eclipses de sol y de luna, pero sobre todo cuando sobreviene el calor tras las lluvias o viceversa (Nat.2.194-195.80).

Uno de los puntos más originales de Plinio frente a Aristóteles es el gran número de signos premonitorios de los terremotos que incluye. Así, en el mar, los navegantes notan que se va a producir un terremoto porque se levanta oleaje de repente sin haber brisa, tiemblan las puertas en las naves e incluso las aves se posan asustadas. Menciona también otro de los signos premonitorios de los que se hace eco Aristóteles, la nube fina que se extiende como una línea a lo largo durante el día. Asimismo, en los pozos el agua se vuelve turbia y de mal olor (Nat.2.196.81).

Luego enumera lo que podríamos considerar un decálogo de medidas de seguridad para protegerse ante un temblor (cf. Nat.2.197.82). Comienza diciendo que las ciudades perforadas por numerosas galerías de desagüe son las más seguras -sin 
duda, por la creencia de que por tales galerías se podría escapar el soplo de viento responsable de un seísmo-. Y por ello la parte más segura de las ciudades es la que se levanta sobre esa red de galerías, siendo la menos segura la que se levanta sobre terreno compacto.

En los edificios los lugares más seguros son los arcos, las esquinas de las paredes y las puertas; también, según Plinio, los muros construidos con ladrillo de adobe aguantan mejor las sacudidas.

A continuación hace una clasificación de los terremotos según sus riesgos (algo similar a lo que ha hecho antes al establecer una tipología de los terremotos según sus efectos): el de menor riesgo es aquel en donde el temblor se acompaña del crujido vibrante de los edificios; también aquel que en un primer momento se levanta y luego vuelve a asentarse; tampoco es muy destructivo aquel seísmo que hace que choquen dos techos y que se empujen presionándose uno contra otro. Los más peligrosos son aquellos en los que se produce una oscilación ondular y cierto balanceo, similar al oleaje, y también cuando todo el movimiento se ejerce en una misma dirección (Nat.2.198, 82).

Plinio cierra el grueso de su explicación diciendo que, cuando cesa el viento, suele cesar el terremoto; en caso contrario, suelen durar cuarenta días e incluso hasta dos años (como ya dijera también Aristóteles).

En Nat.2.200.84 Plinio añade que a veces, a la vez que un terremoto, se producen inundaciones del mar, lo cual es debido a la misma acción del aire. Informa a continuación de algunos de los peores terremotos que conocieron los tiempos antiguos. Cierra su exposición afirmando el carácter de presagio que se asigna a los terremotos: cualquier temblor anuncia cosas peores, como sucedía en Roma, que nunca tembló sin que eso fuera el anuncio de algún futuro percance. Este carácter de presagio funesto que los antiguos asignaban a los terremotos, del que Plinio se hace aquí eco, contrasta con su intento de racionalizar al máximo un fenómeno natural de gran alcance como es un seísmo.

En su exposición, Plinio conjuga lo que toma de los autores anteriores que han hablado sobre el tema, sobre todo Aristóteles, con su propia experiencia, que enriquece lo que esos mismos autores han dicho. Atribuimos más al conocimiento que tiene del fenómeno por su propia experiencia que a lo que haya podido leer en la literatura anterior sobre el tema su intento por establecer una tipología de seísmos tan exhaustiva, basada en criterios tales como sus efectos o sus riesgos, el tipo de ruido que suele preceder y acompañar a la sacudida sísmica (y que depende del tipo de material que expulsan y la forma de las galerías que atraviesan) o el tipo de grietas. Lo que ocurre es que no llega a dar nombres concretos a tales tipos de seísmos, a pesar del gusto de este autor por las tipologías y las clasificaciones. Fruto también de su experiencia o por haberlo leído en fuentes literarias es la relación de signos premonitorios o el breve «decálogo» de medidas de seguridad que enumera. 


\subsection{SÉNECA Y SU ESTUDIO SOBRE LAS POSIBLES CAUSAS DE LOS SEÍSMOS}

El último autor de esta relación es Séneca, quien dedicó un libro completo de sus Naturales Quaestiones ${ }^{33}$, el sexto, al tema de los terremotos y que, según confesión propia (Nat.6.4.3), en su juventud ya había redactado un volumen de motu terrarum que, por desgracia, no conservamos ${ }^{34}$. Este libro sexto constituye el testimonio antiguo más amplio sobre los seísmos abordados desde una perspectiva digamos científica, aunque es bien cierto que muchas de las páginas de su tratado abordan más bien cuestiones morales ${ }^{35}$.

Que el enfoque desde el que Séneca aborda la cuestión es absolutamente racional ${ }^{36}$ queda fuera de duda, cuando en Nat.6.3.1 afirma que los dioses no intervienen en ellos ni se deben a la ira de las potencias divinas, sino que estos fenómenos tienen sus propias causas que no obedecen a ningún mandato digamos externo.

Una de las principales aportaciones de Séneca a la discusión sobre las causas y naturaleza de los seísmos en la Antigüedad es el haber recogido, aunque sea de forma muy resumida, el testimonio de un buen número de autores antiguos sobre el particular, de muchos de los cuales no conservamos obra alguna. Todos estos testimonios aparecen agrupados según sea la causa que cada uno de ellos alega como motivo desencadenante de los seísmos ${ }^{37}$. Como veremos, en muchos casos Séneca

${ }^{33}$ Para el texto latino y la traducción española nos hemos servido de Codoñer Merino 1979. Un artículo muy interesante para situar este tratado sismológico de Séneca dentro de la tradición antigua sobre el tema es el de Williams 2006, si bien su objetivo esencial es analizar en detalle las estrategias retóricas que usa Séneca en su exposición con el objetivo de combatir el miedo que los terremotos producen en el hombre. Dichas estrategias se resumen en apartar la atención de lo particular y dirigirla hacia lo general, y hacer percibir que nuestra existencia particular y los sucesos a ella asociados están integrados en la totalidad del cosmos.

${ }^{34}$ Una muy breve mención a las distintas causas de los terremotos la tenemos también en el De ostentis de Juan Lido, en su capítulo 53, donde se destaca como causa fundamental el fuego subterráneo, apoyándose tanto en lo que dijeron los antiguos filósofos como en lo que, según él mismo dice, pudo observar con sus propios ojos en las regiones que suelen verse más afectadas por movimientos sísmicos. Añade como prueba de que el fuego es la causa principal el hecho de que las regiones cercanas a manantiales de agua caliente sufren con más frecuencia movimientos sísmicos.

${ }^{35}$ El motivo inmediato que supuestamente llevó a Séneca a redactar su tractatus sobre los movimientos sísmicos es el de consolar a la gente por el miedo que se apoderó de ellos tras el terremoto registrado en la Campania, en particular en Pompeya, Herculano y regiones colindantes, en el año 62 o 63, pero en todo caso anterior al gran cataclismo de agosto del 79. Para ello trata de encontrar una explicación racional a tales tipos de movimiento, sin dejar de recomendar fortalecer el ánimo acabando con el miedo a la muerte, que es el que nos hace débiles (Nat.6.32.9). Se trata, en el fondo, del mismo objetivo que llevó a Lucrecio a tratar el mismo tema en el libro $6^{\circ}$ de su De rerum natura (sobre esto, $c f$. Williams 2006, p.125).

${ }^{36}$ De hecho Séneca es considerado por algunos autores como uno de los últimos representantes del saber racionalista positivo en época romana ( $c f$. Traina 1989, p.110).

${ }^{37}$ La exposición de Séneca sobre los terremotos se caracteriza por su gradualidad: da al lector una panorámica general muy completa sobre las distintas opiniones surgidas a lo largo del tiempo acerca de la causa del fenómeno -algunos ponen su causa en el agua, otros en el fuego, otros en la tierra misma, otros en el aire, otros en varios de estos elementos, otros en todos ellos e incluso hubo quien dijo que la causa era una de las mencionadas aunque sin determinar cuál de ellas (Nat.6.5.1)-, antes de exponer en detalle la suya propia (aunque algo siempre adelanta al explicar las teorías de los demás). Sobre el testimonio de los antiguos su opinión no puede ser más clara: opiniones ueteres parum exactas esse et rudes (Nat.6.5.2), es decir, eran poco exactas y poco trabajadas, debido a la novedad de la materia para los que hicieron estos primeros intentos. Por eso pide a sus lectores comprensión para estos primeros testimonios (cum excusatione itaque ueteres audiendi sunt, Nat.6.5.3). 
refutará sus explicaciones, pero en otros las admite e incluso las refuerza o amplía con argumentos propios, pues en el fondo, aunque él admitirá una causa como la fundamental -el aire, como ya veremos-, deja entrever que no se pueden descartar otras muchas.

Entre los que alegan como causa el agua su principal defensor fue Tales de Mileto (Nat.6.6), para quien la tierra entera flota sobre el agua como si de una nave grande y pesada se tratara. Para demostrar que el agua estaba detrás de los seísmos, Tales afirmaba que en todos los movimientos de una cierta importancia solían brotar manantiales. Séneca refuta esta teoría diciendo que si el agua fuera la causa, la tierra estaría en constante movimiento y no quieta, como es lo habitual; y, además, que se vería afectada toda ella y no sólo una parte, como se ve que ocurre, dado que los seísmos son fenómenos muy localizados.

En Nat.6.7 afirma que otros autores, que no menciona, alegan que el agua está detrás de los terremotos, pero por razones distintas a las aludidas por Tales de Mileto. En efecto, igual que en la superficie terrestre hay ríos de muy diverso tipo, lagos y pantanos, algo similar debe ocurrir en el interior de la tierra; por ello no se puede descartar que, al salirse de su cauce un río subterráneo, el agua azote con fuerza los obstáculos que se encuentre, provocando el movimiento de la zona azotada. Séneca, que admite esta posible causalidad, añade que igual que hay un mar en torno a las tierras superficiales, debe haber otro interior que al bajar y subir de nivel conmocione las zonas superpuestas. Como complemento a lo dicho en este capítulo, en Nat.6.8 agrega otras pruebas para demostrar que existen ríos subterráneos y un mar oculto.

La siguiente causa que analiza es la de los que ponen al fuego como motivo de los terremotos, siendo su representante más destacado Anaxágoras, que, según Aristóteles, ponía en el aire seco la causa de los seísmos. Según expone Séneca (Nat.6.9.1), para Anaxágoras, igual que sucede con el aire exterior, en el interior de la tierra a veces una corriente de aire puede disgregar el aire acumulado en forma de nubes, produciéndose fuego como consecuencia de la colisión. A continuación el aire expulsado choca contra cualquier obstáculo que encuentre en su intento por encontrar una salida hacia el aire libre ${ }^{38}$. También refiere (Nat.6.9.2-3) la idea de otros, que no menciona, que dicen que en el interior de la tierra arde en muchos lugares un fuego oculto que consume todo lo que está a su alrededor, provocando el derrumbe de las zonas desgastadas y la consiguiente conmoción de los lugares que se vienen abajo al faltarles los soportes en los que se apoyaban.

En Nat.6.10 se detiene a exponer las tesis de Anaxímenes, del que ya había hablado también Aristóteles. Según Séneca, para este autor la causa de los seísmos está en la tierra misma, sin que intervenga ningún factor externo. En efecto, bien sea por el agua, por el fuego, por el viento o -añade después- por la propia vejez, nunca fal-

\footnotetext{
${ }^{38}$ En realidad, si la interpretación de Séneca es correcta, Anaxágoras debería alinearse con aquellos que ponían al aire como causante de los terremotos, pues en su teoría el fuego no es más que un «efecto colateral» del choque entre una corriente de aire y el aire acumulado en forma de nubes. Lo que realmente produce el movimiento es la corriente de aire expulsada tras el choque en su afán por salir a la superficie.
} 
tan factores que contribuyan a arrancar partes importantes de la misma que, al caer, hacen temblar las zonas superiores, como sucede en los edificios viejos ${ }^{39}$.

El capítulo 11 debe considerarse como una suerte de añadido o excurso, pues en él vuelve a hablar del fuego como causa, rompiendo así el esquema que había establecido en el capítulo 5. Dice que hay algunos autores, que no menciona, que atribuyen a ese fuego que arde en tantos lugares oculto la capacidad de generar una gran cantidad de vapor que presiona por encontrar una salida, agrietando todo lo que se opone.

Retomando el esquema establecido en Nat.6.5, los capítulos 12 a 17 están dedicados a explicar las teorías de los que ponen al aire como causa, que son la mayoría y las máximas autoridades (Nat.6.12.1), aunque con una gran variedad de matices, como ahora vamos a poder comprobar.

El primero del que habla es Arquelao (Nat.6.12.1-2), para quien los terremotos se producen cuando el viento acumulado en el interior de la tierra llena el espacio y se condensa hasta el límite y, al ser empujado por nuevas masas de aire, intenta encontrar una salida, momento en que golpea la tierra y la conmueve. Por eso, cuando se va a producir un terremoto, hay mucha calma, ya que la masa de aire que provoca los vientos está retenida en el interior de la tierra.

Menciona después a Aristóteles y Teofrasto ${ }^{40}$ (Nat.6.13.1), cuya teoría resume diciendo que los movimientos sísmicos se deben al choque del aire que va y viene ${ }^{41}$ en el interior de la tierra al golpear los obstáculos, ya sea que se quede encerrado, ya que intente atravesar por zonas estrechas.

Más espacio dedica a la explicación de Estratón (Nat.6.13.2-6), para quien la causa de los seísmos está en el especial comportamiento que tienen el aire caliente y el frío que hay en el interior de la tierra. En efecto, lo frío y lo cálido no pueden estar unidos: una masa de aire frío ocupa el espacio abandonado por una masa de aire cálido, y lo cálido ocupará el espacio del que ha sido desalojado el aire frío. De este modo, cuando una masa de aire, digamos frío, ocupa las grutas donde antes estaba el aire cálido, éste, reducido a ocupar los espacios más estrechos, se revuelve y lucha por salir, golpeando y destrozando todo lo que encuentra. Este comportamiento es el mismo cuando es el aire cálido el más poderoso.

En el capítulo 14 resume dos teorías, de las que la segunda complementa y precisa a la primera, de unos autores que no menciona y que explican la acción del aire de otro modo. La primera de las teorías (Nat.6.14.1-2) compara la tierra con un cuerpo vivo $^{42}$, con sus conductos para la sangre, el agua en el caso de la tierra, y el aire, el

\footnotetext{
${ }^{39}$ A pesar de las diferencias de matiz, las explicaciones de Aristóteles y de Séneca respecto a la teoría de Anaxímenes son coincidentes en el hecho de que es la disgregación y caída de partes de la tierra, por factores diversos, lo que provoca los seísmos. De esta misma opinión es Marmo 1989, p.172.

${ }^{40}$ Teofrasto habría considerado como causa de los terremotos no sólo la teoría aristotélica del pneuma sino también los derrumbamientos internos de la tierra (cf. Marmo 1989, p.175).

${ }^{41}$ Este ir y venir del aire forma parte del movimiento de las emanaciones terrestres, unas secas y otras húmedas, que ascienden desde las profundidades y que cuando ya no pueden elevarse más vuelven atrás y recaen sobre sí mismas.

42 Se trata de la teoría del estoico Posidonio, que hace aún más estrecha que en Aristóteles la comparación entre el comportamiento del cuerpo humano y los terremotos. Sobre esto, $c f$. Marmo 1989, p.175.
} 
mismo que recorre la tierra a modo de respiración. Cuando el cuerpo funciona normalmente, no se producen alteraciones; en caso de enfermar se pueden producir convulsiones. De este modo podríamos entender que los terremotos se corresponden con las convulsiones que demostrarían que la tierra está, digamos, enferma. El problema de esta teoría, según Séneca, es que si creemos que la tierra es un organismo vivo, las conmociones, es decir, los terremotos, tendrían que afectarla en su conjunto, como vemos que sucede con la fiebre, cuando sabemos que los terremotos son fenómenos bastante localizados.

Por eso, y aquí viene la segunda teoría (Nat.6.14.3-4), la única forma de explicar los terremotos como fenómenos localizados sería aceptando que entra aire desde fuera, que sólo cuando encuentra algún obstáculo que le impida salir actúa como ya se ha dicho muchas veces, golpeando y destrozando el obstáculo que se interpone en su camino.

Siguiendo con el aire como causa, en el capítulo 15 se expone la teoría de aque$\operatorname{llos}^{43}$ que afirman que el aire entra en la tierra no sólo por sus primitivos accesos sino por otras hendiduras o poros causados normalmente por la erosión del agua (torrentes y mareas). Cuando esas hendiduras se taponan, el aire pierde cualquier posibilidad de retirada, y no pudiendo moverse en línea recta, como es lo natural en él, se ve obligado a ascender en altura, golpeando así la tierra que le cierra el paso.

Por su parte, los capítulos 16 y 17 siguen abundando en la explicación del aire como causa de los terremotos. En principio, el 16 insiste en la vinculación de la tierra y el aire, el cual le proporciona cohesión e incluso se encuentra dentro de las piedras. Menciona también la teoría aristotélica de los efluvios terrestres de los que se sustentan los cuerpos celestes y cómo éstos a su vez se lo devuelven. Por ello hay que suponer que la tierra está llena de aire que, como el elemento más móvil que es, le provoca frecuentes conmociones. Por su parte, el capítulo 17 explica la mecánica, ya tantas veces repetida, de cómo el aire es capaz de conmover la tierra, al no encontrar una salida adecuada (por lo que actúa como el agua durante una riada).

Justamente, cuando Séneca ha comenzado a exponer en detalle su opinión sobre la causa de los seísmos, en el capítulo 20 resume la opinión de aquellos que creían que el fenómeno se debía no a una única causa o elemento, sino a muchas. Entre ellos cita a Demócrito, cuya opinión ya resumía Aristóteles, para quien los movimientos sísmicos se producen unas veces por el aire, otras por el agua y en otras ocasiones por ambos elementos (Nat.6.20.1-4); y a Epicuro, que admite las causas alegadas por Demócrito y algunas más: la tierra puede ser conmovida por el agua, por el aire, por un soplo caliente que actuara como el rayo, por un soplo de aire que agitara aguas pantanosas, entre otras, aunque reconoce que el aire es la causa fundamental (Nat.6.20.5-7). La duda de Epicuro de que haya una única causa es más bien metodológica: es arriesgado hablar con certeza de materias que hay que dilucidar mediante conjeturas (Nat.6.20.5) ${ }^{44}$.

\footnotetext{
${ }^{43}$ Se trataría de Diógenes de Apolonia, contemporáneo de Anaxágoras y posiblemente discípulo de Anaxímenes, y sería el primero en defender la teoría del aire como causa de los seísmos. Sobre esto, $c f$. Marmo 1989, pp.172-173.

${ }^{44}$ Sobre las teorías pluralistas acerca de los terremotos, $c f$. Marmo 1989, pp.176-177.
} 
En fin, vistas en detalle las causas alegadas de los terremotos, Séneca defiende que la principal es el aire, dada su naturaleza móvil, al desplazarse de un lugar a otro (Nat.6.18.1; 21.1 y 24.1). Al poner al aire como maxima causa, indirectamente admite que los demás elementos pueden tener una cierta participación, por pequeña que sea.

Respecto al comportamiento del aire, la experiencia demuestra que, cuando se le empuja y arrincona, si le es posible, al principio se limita a ceder terreno; pero, cuando ya no tiene posibilidad de retirarse y encuentra resistencia por todas partes, entonces ruge (Nat.6.18.2). En efecto, ningún obstáculo puede contener ni retener al viento (Nat.6.18.3), nada en la naturaleza es más poderoso ni activo que él (Nat.6.21.1).

Asimismo, sostiene que el aire que provoca el seísmo es el que la tierra contiene por sí misma en sus profundidades, negando al mismo tiempo que el aire entre en la tierra desde la superficie terrestre a través de unos supuestos poros que la tierra tuviera. Compara la situación con lo que ocurre en nuestro cuerpo con la piel, que escupe el aire y éste no entra sino por los cauces naturales por los que se desliza (entiéndase los órganos relacionados con la respiración) (Nat.6.24.1-2).

Este aire interior, cuando se acumula en grandes cavernas subterráneas situadas en las profundidades de la tierra, al intentar encontrar una salida, golpea las paredes de dichas cavernas, sacudiendo y echando por tierra los edificios que se encuentran situados encima. Pero cuando las sacudidas son tales que echan abajo toda la techumbre del espacio hueco interior, las ciudades que estuviesen situadas sobre tal techumbre se precipitarían en las profundidades.

La prueba más palpable de que el aire se acumula exclusivamente en grandes cavernas es el carácter localizado de los terremotos: según Séneca, éstos no suelen afectar a áreas extensas, pues el movimiento nunca alcanza doscientas millas (Nat.6.25, 3). Es decir, que el área afectada por un terremoto coincide con la extensión de la caverna interior de la tierra donde se acumula el aire.

Niega también la opinión de aquellos que creen que las islas y las ciudades situadas cerca de las costas están más a salvo de sufrir un terremoto que el resto, algo que desmienten los sucesos de Pompeya y Herculano.

Para explicar por qué murieron gran número de ovejas tras el terremoto en la región de Pompeya, Séneca afirma que después de los grandes seísmos no es raro que se presenten pestes y epidemias por la liberación súbita del aire enrarecido encerrado en la tierra; esto mismo sucede con el agua interior que aflora tras los grandes terremotos (Nat.6.27.2).

\subsection{LA TIPOLOGÍA DE LOS SEÍSMOS DE SÉNECA Y EL PAPEL DE POSIDONIO}

Además de hacer un completo recorrido por los diversos factores que desencadenan los terremotos, Séneca establece también una tipología de este tipo de movimientos, tomando los dos tipos que distinguía Posidonio y añadiendo a éstos un tipo más (Nat.6.21.2).

En efecto, Posidonio hablaba de un primer tipo al que llamaba «convulsión» (succussio ) -cuando la tierra recibe las sacudidas moviéndose de arriba abajo y de abajo arribay un segundo tipo denominado «inclinación» (inclinatio) -en el que la tierra oscila alter- 
nativamente hacia los lados, como los barcos-- El tercer tipo, añadido por Séneca, se denomina «temblor» de tierra (tremor terrae); en él los objetos no sufren convulsiones ni oscilaciones, sino que vibran. Es este el tipo de movimiento sísmico menos peligroso, siendo la «inclinación» el más dañino si, cuando se produce, no viene a continuación un movimiento en sentido contrario que compense y que evite los derrumbamientos.

Asimismo, la simple comparación entre la taxonomía de seísmos que aparece en el Peri kosmou y en el De mundo con la que expone Séneca nos revela inmediatamente algunas coincidencias reveladoras. Por lo pronto, el tipo denominado succussio o convulsión, que implica sacudidas verticales (de arriba abajo y viceversa) son similares al tipo denominado brastae, donde los objetos se elevan verticalmente por efecto de la sacudida; la inclinatio es idéntica al tipo denominado epiclintae, donde se producen desplazamientos hacia los lados (precisamente, el verbo griego غ̇ $\pi \iota \lambda i ́ v \omega$ significa 'inclinar'); en fin, el tipo general denominado por Séneca tremor terrae o temblor de tierra, que supone la mera vibración de los objetos (por ser un seísmo de escasa intensidad), se parece mucho al tipo denominado palmatiae, donde a pesar de las sacudidas los objetos conservan su verticalidad.

Según confiesa Séneca, los dos primeros tipos, la succussio (= brastae) y la inclinatio (= epiclintae), proceden de Posidonio de Apamea (c. 135-51 a. C.), quien es sabido que escribió, entre otros temas, sobre cuestiones de meteorología, entre las cuales se cuentan -como estamos viendo- los terremotos; y en estos temas, a pesar de ser estoico, se mostró como un continuador de Aristóteles ${ }^{45}$. En efecto, aunque en su exposición sobre el tema Aristóteles no estableció expresamente una tipología de los seísmos, sí hemos visto que se puede, sin dificultad, distinguir, entre otros, un tipo de sacudida a lo ancho, es decir, lateral (la inclinatio), y otra donde la tierra es sacudida de abajo arriba (la succussio). Pero es que incluso el tipo general del tremor terrae, mera vibración, podría corresponderse con ese tipo de seísmo del que habla Aristóteles donde hay ruido pero sin sacudida.

Pero no termina aquí la cuestión de la tipología posidoniana de los seísmos. En efecto, en su Vitae philosophorum 7.154.8-10 Diógenes Laercio afirma que Posidonio, en su libro octavo (quizás, de un tratado de meteorología o de física), habla de

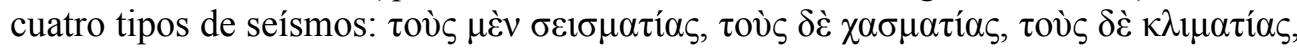

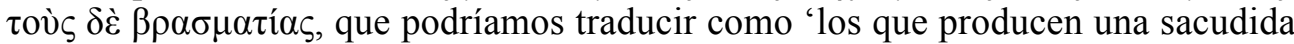
violenta de la tierra', 'los que producen grietas', 'los que hacen oscilar la tierra hacia los lados' (de $\kappa \lambda i ́ \mu \alpha$, 'inclinación, pendiente') y 'los que la agitan sacudiendo el suelo verticalmente' (de $\beta \rho \alpha ́ \sigma \mu \alpha$, 'burbujeo', 'agitación', 'estremecimiento').

Independientemente de la discordancia con lo apuntado por Séneca, lo importante es que de nuevo nos encontramos aquí ante una clasificación que, en lo esencial, coincide con lo que encontramos en el Peri kosmou. En efecto, el tipo denominado

\footnotetext{
45 Según Helly 1983, p.66, Posidonio fue para la sismología antigua una figura de primer orden: profundizó y amplió el campo de la sismología griega; en sus múltiples viajes se interesó por todas las zonas sísmicas del Mediterráneo; reconoció la universalidad de los fenómenos sísmicos, pero también las manifestaciones locales basadas en particularidades geológicas; en fin, advirtió que los terremotos no eran sólo fenómenos de la superficie de la tierra, sino que podían localizarse a grandes profundidades.
} 


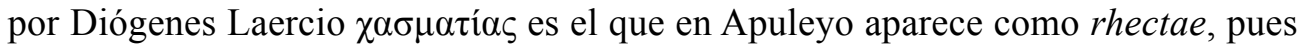
implica la aparición de grietas en la tierra; el tipo denominado $\kappa \lambda \iota \mu \alpha \tau i ́ \alpha \varsigma$, que implica inclinación u oscilación lateral del terreno, es el llamado inclinatio por Séneca y

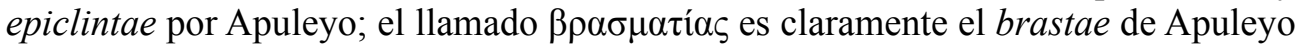
y, por tanto, el que Séneca denomina succussio. En fin, el tipo que Diógenes Laercio denomina $\sigma \varepsilon 1 \sigma \mu \alpha \tau i ́ \alpha \varsigma$, que parece implicar una sacudida más o menos violenta de la tierra, podría corresponder al tipo que Apuleyo llama ostae o al denominado palmatiae, según supongamos más o menos violenta la sacudida ${ }^{46}$.

Ante tanta coincidencia, es obvio suponer una relación directa entre la clasificación de Posidonio y la que exhiben el Peri kosmou y el De mundo. El problema es determinar de quién sobre quién. Si suponemos, como hace Reale, que el Peri kosmou es una obra auténtica de Aristóteles, escrita cuando éste fue preceptor de Alejandro - por lo que podría ser el manual de filosofía que el Estagirita habría redactado para el joven príncipe- ${ }^{47}$, y que la parte meteorológica, a la luz de los últimos descubrimientos, no procedería de Posidonio, como tradicionalmente se había supuesto, sino de Teofrasto $^{48}$, quien habría retocado la obra, limitándose a dicha parte, donde habría incorporado sus propios descubrimientos ${ }^{49}$, sería el filósofo estoico el que está tomando la clasificación del Peri kosmou ${ }^{50}$. En cambio, si como supone una parte de la crítica -y nosotros con ella- que la obra es espuria y quizás de un periodo que va del s. I a. C. hasta comienzos de la época imperial ${ }^{51}$, sería más bien el tratado pseudoaristotélico el que bien pudo tener en cuenta la clasificación posidoniana para establecer la suya.

Pero en Séneca, aunque es en Nat.6.21.2 donde se establece una tipología clara con denominación concreta y determinada de los seísmos, ya en Nat.6.4.1., cuando

\footnotetext{
${ }^{46}$ Sobre esta identificación, $c f$. Kidd 1988, pp.817-818. De otro lado, tres de los tipos de terremotos posi-

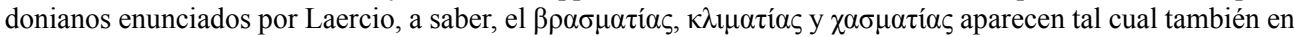
las Alegorías de Homero de Heráclito el Rétor, 38.6 (de finales del s. I a. C. o principios del I d. C.) y en Amiano Marcelino, del que hablaremos después. Se trataría, por tanto, de una prueba más de que la influencia de Posidonio en este punto fue notable.

${ }^{47}$ Reale - Bos $1995^{2}$, pp.17-18.

${ }^{48}$ Reale - Bos $1995^{2}$, pp.140-141, en particular n. 95. De hecho, en p.299 se informa de que el tipo de te-

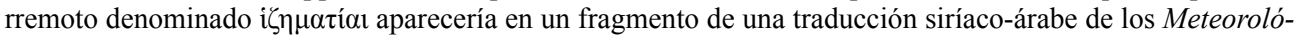
gicos de Teofrasto, según señala Strohm.

${ }^{49}$ Reale - Bos $1995^{2}$, p. 143 .

${ }^{50}$ Reale - Bos, $1995^{2}$, p.299: «Infine vi è un ultimo punto da relevare: la tavola delle differenti specie di terremoti che leggiamo in De mundo è la più completa che gli autori antichi ci abbiano tramandata. [...] Da questo preciso dato di fatto si dovrebbe inferire che il De mundo sia stato la fonte da cui gli altri (mediatamente o inmediatamente) hanno attinto, non viceversa: $[\ldots] »$.

${ }^{51}$ Siguiendo la bibliografía razonada de Reale - Bos $1995^{2}$, pp.367-399 y nuestras propias indagaciones ofrecemos, como botón de muestra, algunos de los autores que han defendido una datación tardía del Peri kosmou. Bücheler 1882, 294-295 retoma la tesis de Th. Bergk que consideraba a Nicolás de Damasco, que vivió en la época de Augusto, como el autor del tratado; Lorimer 1924 lo data entre el 40 y el 140 d. C., pues,

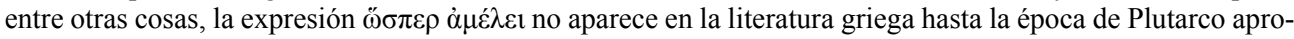
ximadamente; para Festugière 1949 el autor sería un peripatético influido por Posidonio, por lo que la fecha de composición tendría que ser tardía; Moraux 1984 defiende la influencia de Posidonio y que se redactara en la época de Filón de Alejandría; Schönberger 1991 sugiere que el tratado pudo ser compuesto en torno al año 80 d. C., en la época de Domiciano; Mansfeld 1992 considera que el tratado se compuso a finales del siglo I a. C. por un peripatético con inclinaciones platonizantes.
} 
expresa su intención de investigar las causas que pueden hacer mover la tierra desde su interior o empujar una masa tan grande, hace un recorrido por las distintas manifestaciones asociadas con los movimientos sísmicos que muy bien podría tomarse como un esbozo de tipología.

Así, empieza preguntándose por qué unas veces el terremoto se limita a una simple vibración y en otros casos se producen desmoronamientos; por qué en otras ocasiones separa la tierra en partes; en unos casos mantiene mucho tiempo la abertura que crea; en otros la cierra rápidamente. En ocasiones hace brotar ríos. A veces hace salir venas de agua caliente; otras veces las enfría; en ocasiones deja salir fuego por los resquicios que crea, aunque otras veces elimina los resquicios conocidos durante mucho tiempo. En fin, comparemos la tipología que podemos leer en el texto apuleyano y reconoceremos inmediatamente en esta descripción de los comportamientos de los distintos tipos de seísmos algún otro de los tipos de terremotos en él señalados, en concreto, los denominados hizematiae, que hunden el terreno, y los rhectae, que lo desgarran y entreabren.

Es decir, ya en Séneca, el último gran tratadista antiguo sobre los terremotos, encontramos en ciernes lo que es la principal aportación del De mundo y, evidentemente, del Peri kosmou, en este tema, una cuidada clasificación de los distintos tipos de terremotos designados con términos precisos, basada en su comportamiento aparente. Un estudio detallado de la presencia de esas mismas denominaciones concretas en la literatura posterior puede servirnos, entre otras cosas, como indicio de la influencia que el De mundo o el tratado griego original ejercieron.

\section{LA TIPOLOGÍA DE LOS SEÍSMOS DEL PERI KOSMOU Y EL DE MUNDO Y SU POSIBLE INFLUENCIA}

Ciñéndonos a la literatura latina, si nos atenemos a lo que dice el $T h L L$ y el Thesaurus Formarum Latinarum, los términos epiclintae, brastae, rhectae, ostae palmatiae y mycetias sólo están atestiguados en Apuleyo, mientras que hizematiae ni siquiera aparece recogido en ninguno de estos dos Thesauri -en su lugar se recoge la forma chasmatiae, atestiguada tanto en Apuleyo como en Amiano Marcelino. No obstante, y esto quizás podría tomarse como un indicio de una posible influencia del De mundo, en Amiano Marcelino aparecen recogidos, si bien con nombres ligeramente diferentes, dos de estos tipos de seísmos ${ }^{52}$ :

a) El tipo denominado brastae es llamado por el historiador latino brasmatiae en 17.7.13:

[...] aut enim brasmatiae sunt, qui humum more aestus imitus suscitantes, sursum propellant immanissimas moles, $[\ldots]^{53}$

[existen cuatro clases de terremotos] pues estos son brasmatiae, los cuales levantando el suelo desde el fondo como hace la marea, empujan hacia arriba enormes masas.

\footnotetext{
${ }^{52}$ Amiano Marcelino se hace eco en 17.7.11-12 de algunas de las teorías aquí vistas acerca de la causa de los terremotos, en particular, las de Aristóteles, Anaxágoras y Anaximandro.

${ }^{53}$ El texto de Amiano Marcelino que manejamos es el de la edición de Rolfe 1982-1986.
} 
b) Por su parte, el tipo denominado mycetias es designado por Amiano Marcelino como mycematias en 17.7.14:

[...] mycematiae sonitu audiuntur minaci, cum dissolutis elementa compagibus, seud assiliunt, uel relabuntur considentibus terris. Tunc enim necesse est uelut taurinis reboare mugitibus, fragores fremitusque terrenos.

Los mycematiae se oyen con un sonido amenazador, cuando los elementos, una vez rota su trabazón, saltan por sí mismos y vuelven hacia atrás cuando el suelo se asienta. Pues entonces necesariamente los estruendos y ruidos sordos de la tierra resuenan como si fueran los mugidos de un toro.

Además, Amiano Marcelino menciona otros dos tipos de seísmos, los denominados climatiae y chasmatiae en 17.7.13:

[...] aut climatiae qui limes ruentes atque obliqui, urbes aedificia montesque complanant $[\ldots]$

o climatiae, los cuales precipitándose hacia un lado y oblicuamente, destruyen ciudades, edificios y montañas.

[...] aut chasmatiae qui grandiore motu patefactis subito voratrinis, terrarum partes absorbent, $[\ldots]$

o chasmatiae, los cuales con su enorme movimiento abren repentinamente simas y se tragan partes de la tierra.

Respecto al origen de esta clasificación, recordando lo dicho más arriba sobre los tipos de seísmos que distinguía Posidonio según el testimonio de Diógenes Laercio, tres de los tipos que aparecen en Amiano Marcelino coinciden con otros tantos de los tipos posidonianos, a saber, los denominados brasmatiae, climatiae y chasmatiae; en cambio, el tipo denominado por el autor latino como mycematiae sólo lo ha podido sacar del De mundo o, en su defecto, del original griego. El hecho de que Amiano Marcelino caracterice este tipo de terremoto sólo por su referencia al mugido que produce cuando se desencadena, y que no diga nada de un olor infecto, nos lleva a descartar como fuente a Apuleyo o al texto griego que éste manejó, donde, como venimos diciendo, es posible que apareciera $\beta \rho \tilde{\omega} \mu \mathrm{ov}$, y nos hace suponer que este empleó la versión más estándar del Peri kosmou, la que presenta la lec-

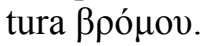

De otro lado, como veremos a continuación, el hecho de que el autor griego Juan Lido haga mención en Ost. 54 a que Apuleyo también escribió sobre los terremotos "con un amplio discurso y en prosa», hace pensar que en su tratamiento del tema y, en concreto, en la clasificación de los seísmos utilizó el De mundo como fuente, antes que el original griego.

Pasando a los autores de lengua griega, la consulta del $T L G$ nos permite verificar que la clasificación que aparece en el Peri kosmou tuvo bastante eco entre algunos autores bizantinos. Lo que sigue es una relación exhaustiva de los tipos de terremotos y de los autores en que aparecen, citando en todos los casos el pasaje donde se encuentra: 


\begin{tabular}{|c|c|}
\hline$\dot{\varepsilon} \pi \mathrm{t} \lambda \lambda \dot{i} v \tau \alpha \mathrm{l}$ & 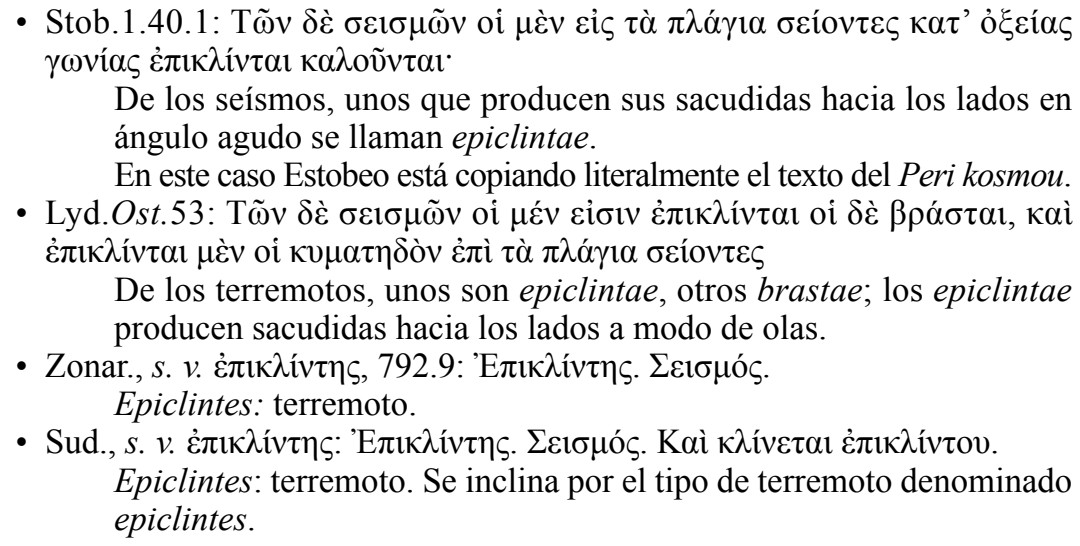 \\
\hline$\beta \rho \alpha ́ \sigma \tau \alpha \imath$ & 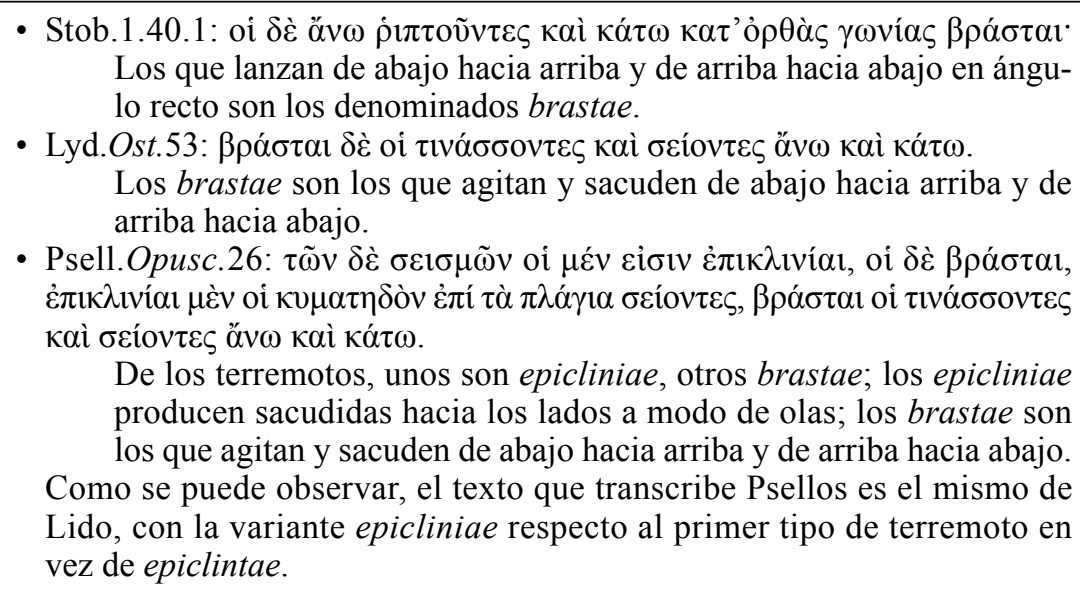 \\
\hline 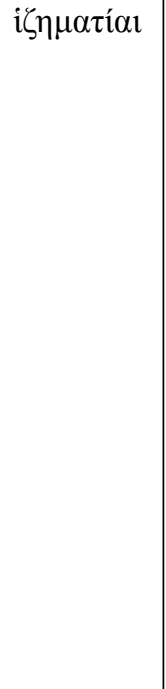 & 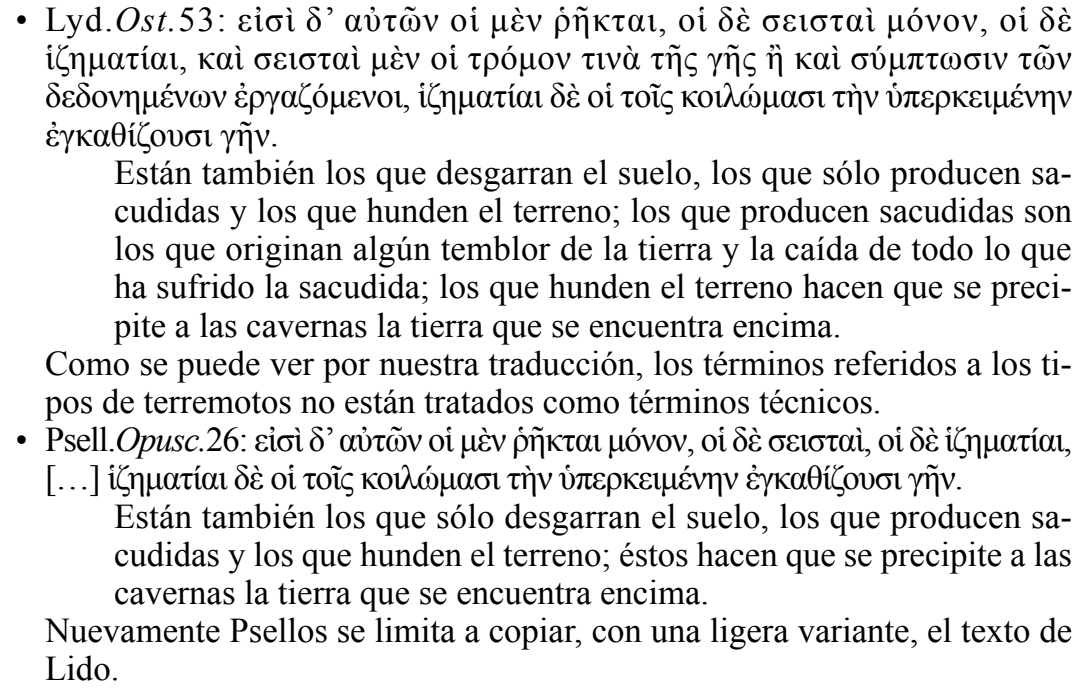 \\
\hline
\end{tabular}




\begin{tabular}{|c|c|}
\hline & 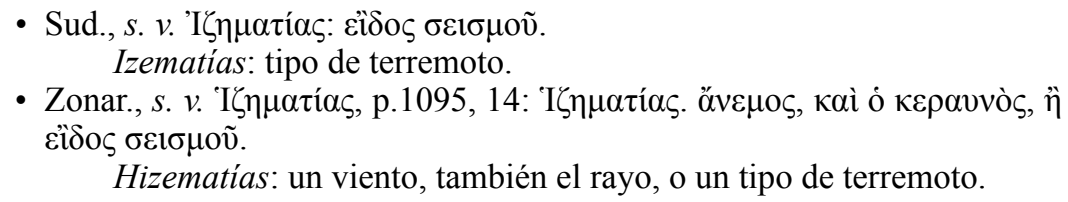 \\
\hline$\dot{\rho} \tilde{\eta} \kappa \tau \alpha \iota$ & 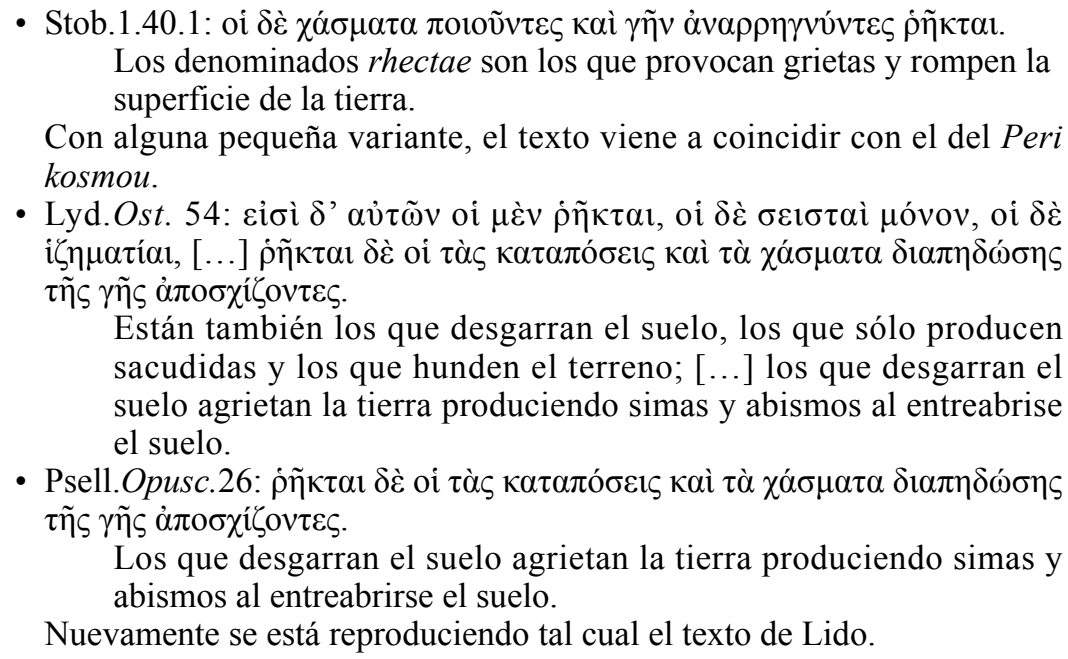 \\
\hline & 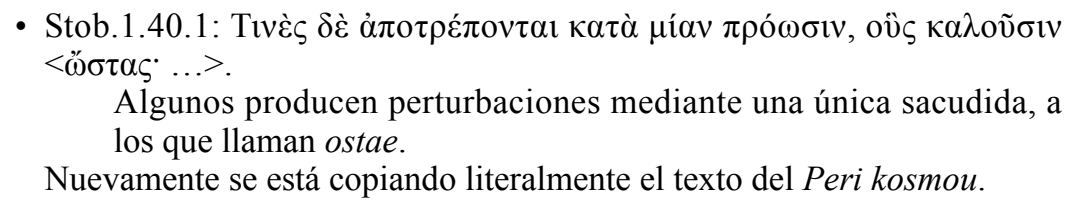 \\
\hline$\Pi \alpha \lambda \mu \alpha \tau i ́ \alpha \imath$ & 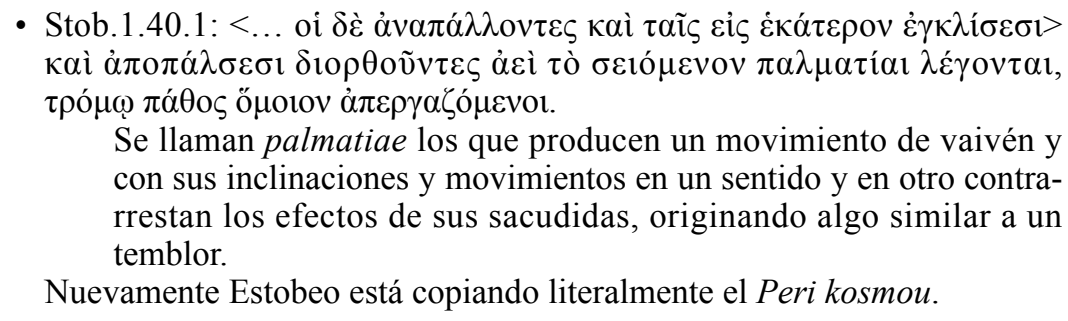 \\
\hline 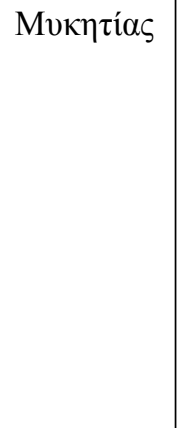 & 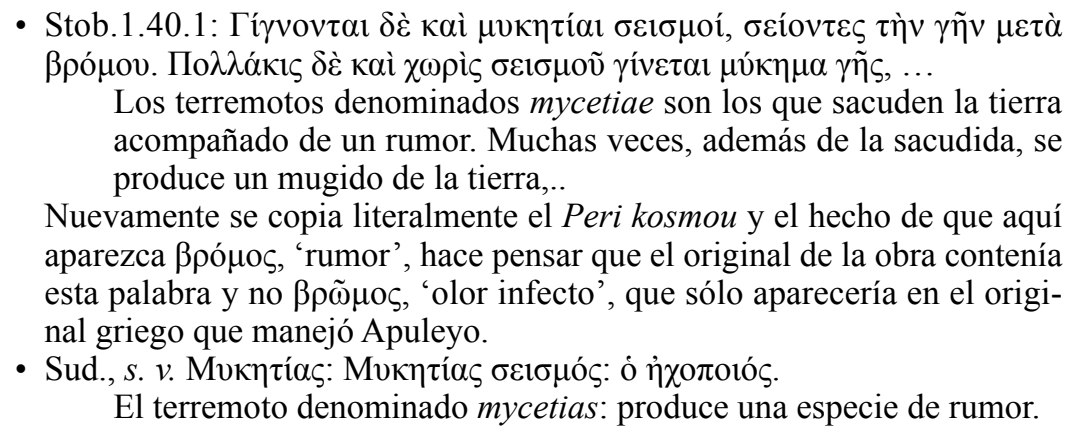 \\
\hline
\end{tabular}


Según la exhaustiva relación que acabamos de hacer, está claro que la clasificación de los tipos de seísmos del Peri kosmou aparece, siquiera parcialmente, en una serie de escritores y obras del periodo bizantino, a saber, el De ostentis de Juan Lido; en obras de doxógrafos como Estobeo, que copia literalmente el Peri kosmou, y Miguel Psellos, que por su parte copia a Lido; y en obras de lexicógrafos, como la Suda y el Pseudo Léxico de Zonaras. A ello se prestaba la curiosidad del tema y el empleo de una terminología casi sin parangón en el mundo antiguo.

Ahora bien, si tenemos en cuenta que es muy posible, por lo dicho más arriba, que Juan Lido utilizara no el texto griego sino el De mundo de Apuleyo ${ }^{54}$, y dado que Psellos parece copiar a Lido, nos encontraríamos ante una inesperada influencia del texto latino, el cual, curiosamente, parece haber tenido poco eco, en este punto concreto, entre los autores de lengua latina.

\section{CONCLUSIÓN}

En fin, como hemos visto en la exposición que precede, el De mundo y el Peri kosmou aportaron a la discusión científica sobre los terremotos en la Antigüedad una precisa clasificación de los mismos sin parangón en ningún otro autor antiguo. En nuestra opinión, esa clasificación, que se basa en las precisas descripciones que ya Aristóteles hizo sobre el comportamiento aparente de los movimientos sísmicos, no es de origen aristotélico, pues en el maestro no se encuentra ni siquiera un esbozo de taxonomía de este tipo de fenómeno telúrico. El hecho de que nuestras fuentes nos informen de que el estoico Posidonio distinguiera hasta cuatro tipos de seísmos, algunos de los cuales se encuentran en otros autores antiguos como Heráclito el Rétor, Séneca, Amiano Marcelino o Juan Lido, además de en el Peri kosmou y en su traducción latina, y que en el propio Séneca se dejara esbozada una clasificación de los seísmos de acuerdo con su comportamiento aparente - sin llegar a constituir una taxonomía-, nos animan a pensar que fue en un contexto estoico donde surgieron los primeros intentos de establecer una tipología de los terremotos de acuerdo con el modo como sacudían la tierra y por los efectos aparentes de tales sacudidas ${ }^{55}$. De hecho, si el Peri kosmou fuera anterior a Posidonio -por ejemplo, de Aristóteles, con algunas aportaciones de Teofrasto en la parte meteorológica, como supone Reale-, no se entendería bien por qué el filósofo estoico no distinguió los mismos tipos de seísmos y con los mismos nombres que habría encontrado en este tratado, dado el carácter fundamentalmente técnico del mismo.

\footnotetext{
${ }^{54}$ Sin embargo, como informan Reale - Bos $1995^{2}$, p.298, n. 173, las notables coincidencias entre Juan Lido, Ost.53 y el Peri kosmou / De mundo, no han sido consideradas suficientes por la crítica para suponer una influencia directa de este tratado sobre el autor bizantino, sino que se ha postulado una fuente común a ambos, a saber, Posidonio.

${ }^{55}$ Esta es más o menos la tesis que defiende Ringshausen 1929, quien tras comparar la clasificación de los terremotos del Peri kosmou con las de los autores antiguos llegados hasta nosotros, concluye que el autor del Peri kosmou pudo basarse en dos autores estoicos Posidonio y Asclepiodoto: adoptó el método de Asclepiodoto y lo combinó con las observaciones de Posidonio.
} 
Por todo ello parece lógico suponer que estamos ante una prueba de que el Peri kosmou se redactó por un seguidor de la escuela aristotélica, pero que conocía también el estoicismo y sus aportaciones, en este caso, a la ciencia sismológica, moviéndose así en un sincretismo muy propio del periodo en torno a los comienzos de la época imperial.

De este modo, la clasificación de los terremotos que aparece en el De mundo de Apuleyo, traducción bastante fiel de la correspondiente del Peri kosmou griego, supuso una especie de broche de oro a los estudios de sismología antiguos, pues habrá que esperar algunos siglos, hasta la época bizantina, para encontrarla, aunque sea parcialmente, en otros autores que se acercaron al fenómeno con un interés anticuario, en la mayoría de los casos.

\section{REFERENCIAS BIBLIOGRÁFICAS}

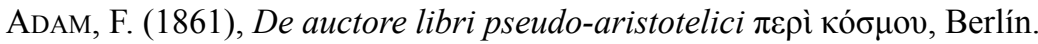

Axelson, B. (1952), Akzentuierender Klauselrhythmus bei Apuleius. Bemerkungen zu den Schriften De Platone und De mundo, Lund.

BAJONI, M.G. (1994), «Aspetti linguistici e letterari del De Mundo di Apuleio», ANRW, II, 34, $2,1785-1832$.

BARRA, G. (1960-1961), «Il valore e il significato del De deo Socratis di Apuleio», AFLN, IX, 67-119.

BARRA, G. (1966), «La questione dell'autenticità del De Platone et eius dogmate e del De Mundo di Apuleio», RAAN, 41, 127-188.

Beaujeu, J. (2002²), Apulée, Opuscules philosophiques: Du dieu de Socrate, Platon et sa doctrine, Du monde, Fragments, París, Les Belles Lettres.

Bousquet, B. - Dufaure, J.-J. - PÉchoux, P.-Y. (1983), «Connaître les séismes en Méditerranée: de la vision antique à la vision actuelle», en Helly, B. - Pollino, A. (eds.), Tremblements de terre histoire et archéologie. IV èmes Rencontres internationales d'archéologie et d'histoire d'Antibes (2-4 novembre 1983), Valbonne, Association pour la Promotion et la Diffusion des Connaissances Archéologiques, pp.23-37.

BÜCHELER, F. (1882), «Der Verfasser der Schrift perì kósmou», RhM, 37, 294-295.

Candel, M. (1996), Aristóteles, Acerca del cielo. Meteorológicos, Madrid, Gredos.

CAPELLE, N., RE. suppl. VI (1924), s. v. Erdhebenforschung, cols. 344-373.

Châtelain, L. (1909), «Théories d'auteurs anciens sur les tremblements de terre», Mélanges d'archéologie et d'histoire, 29, 87-101, disponible en <http://www.persee.fr/web/revues/home/prescript/article/mefr_0223-4874_1909_num_29_1_6995> [consulta: 0907-2010].

Codoñer Merino, C. (1979), Séneca, Naturales Quaestiones (Español-Latín), 2 vols., Madrid, CSIC.

Domenici, I. - Maderna, E. (2007), Giovanni Lido, Sui segni celesti, Milán, Medusa.

Festugière, A.J. (1949), La révélation d'Hermès Trismégiste, vol. II, Le Dieu Cosmique, París, Lecoffre.

Guidoboni, E. (1989), «Filastrio e l'eresia sull'origine naturale del terremoto», GUIDOBONI, E. (ed.), I terremoti prima del Mille in Italia e nell'area mediterranea, Bolonia, SGA, pp.178-181. 
Helly, B. (1983), «Observations et théories sur les séismes dans les sources historiques grecques», en Helly, B. - Pollino, A. (eds.), Tremblements de terre histoire et archéologie. IV èmes Rencontres internationales d'archéologie et d'histoire d'Antibes (2-4 novembre 1983), Valbonne, Association pour la Promotion et la Diffusion des Connaissances Archéologiques, pp.63-71.

Helly, B. (1989), «La Grecia antica e i terremoti», en Guidoboni, E. (ed.), I terremoti prima del Mille in Italia e nell'area mediterranea, Bolonia, SGA, pp.75-91.

HÜBNER, W. (2003), «L'astrométéorologie dans l'Antiquité classique», en CusseT, CHR. (ed.), La météorologie dans l'Antiquité: entre science et croyance. Actes du Colloque International Interdisciplinaire de Tolouse (2-3-4 mai 2002), Publications de l'Université de Saint-Étienne, pp.75-94.

KIDD, I.G. (1988), Posidonius. Vol. II. The commentary. (II) Fragments 150-293, Cambridge Classical Texts and Commentaries 14B, Cambridge University Press.

LidDELl - SCOTT - JonEs (1996), A Greek-English Lexikon, with a revised supplement, Oxford, Clarendon Press.

LORIMER, W.L. (1924), The Text Tradition of Pseudo-Aristotle De Mundo together with an Appendix containing the Text of the Medieval Latin Versions, Oxford, OUP.

Lorimer, W.L. (1925), Some Notes on the Text of Pseudo-Aristotle De Mundo, Oxford, OUP.

LORIMER, W.L. (1933), Aristotelis qui fertur libellus De mundo / edidit W. L. Lorimer; accedit capitum V, VI, VII interpretatio syriaca ab Eduardo König bonnensi germanice versa, París, Les Belles Lettres.

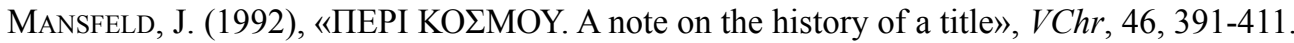

Marchetta, A. (1991), L'autenticità apuleiana del De mundo, L'Aquila, Japadre.

Marcos Casquero, M.A. - Domínguez García, A. (2006), Aulo Gelio. Noches áticas, 2 vols. Universidad de León.

Marmo, C. (1989), «Le teorie del terremoto da Aristotele a Seneca», en Guidoboni, E. (ed.), I terremoti prima del Mille in Italia e nell'area mediterranea, Bolonia, SGA, pp.170-177.

MorauX, P. (1984), Der Aristotelismus bei den Griechen, vol. II, Der Aristotelismus im I und II Jh. n. Chr., Berlín, De Gruyter.

Moreschini, Cl. (1978), Apuleio e il platonismo, Florencia, Leo S. Olschki.

Moreschini, Cl. (1991), Apuleius, De philosophia libri, Stuttgard \& Leipzig, Teubner.

Reale, G. - Bos, A.P. (1995²), Trattato sul cosmo per Alessandro, Milán, Vita e Pensiero.

Regen, F. (1971), Apuleius Philosophus Platonicus. Untersuchungen zur Apologie (De Magia) und zu De mundo, Berlín, De Gruyter.

Ringshausen, K.W. (1929), Poseidonios-Asklepiodot, Seneca und ihre Anschauungen über Erdbeben und Vulkane, Leipzig, R. Noske.

Rodgers, R.H. (1979), «The Apuleius of the Geoponica», California Studies in Classical Antiquity, 11, 197-207.

RoHDE, E. (1885), «Zu Apuleius», RhM, 11, 66-95.

Rolfe, J.C. (1982-1986), Ammianus Marcellinus, Rerum Gestarum, with an English translation by John C. Rolfe, 3 vols., Londres, William Heinemann.

Schönberger, O. (1991), Aristoteles, Uber die Welt, Stuttgart, Philipp Reclam.

Serbat, G. - Fontán, A. - Moure Casas, A. Ma et AL. (1995), Cayo Plinio Segundo, Historia natural, tomo I, libros I-II, Madrid, Gredos.

Squillante, M. (1992), «Tremori nel sottosuolo: angoscia e perdita del fundamento (De rerum natura VI 535-607)», Vichiana, III, 98-116. 
Stahr, A. (1834), Aristoteles bei den Römern, Leipzig, s. n.

Thesaurus Linguae Graecae, CD-ROM-E, 2000, versión on-line $<$ http://www.tlg.uci.edu/> [consulta: 05-09-2010].

TrainA, G. (1989), «Tracce di un'immagine: il terremoto fra prodigio e fenomeno», en GuIDOBONI, E. (ed.), I terremoti prima del Mille in Italia e nell'area mediterranea, Bolonia, SGA, pp.104-113.

VALENTí Fiol, E. (1976), Lucrecio, De rerum natura / De la naturaleza, 2 tomos, Barcelona, Bosch.

Wachsmuth, C. - Hense, O. (1884-1912; reimpr. 1958), Joannis Stobaei anthologium, 5 vols. Berlín, Weidmann.

WaldherR, G. H. (1997), Erdbeben. Das aussergewöhnliche Normale. Zur Rezeption seismischer Aktivitäten in literarischen Quellen vom 4. Jahrhundert v. Chr. bis zum 4. Jahrhundert n. Chr., Stuttgart, Franz Steiner.

Williams, G.D. (2006), «Greco-Roman Seismology and Seneca on Earthquakes in Natural Questions 6», JRS, 96, 124-146. 